\title{
The hemodynamic initial-dip consists of both volumetric and oxymetric changes correlated to localized spiking activity
}

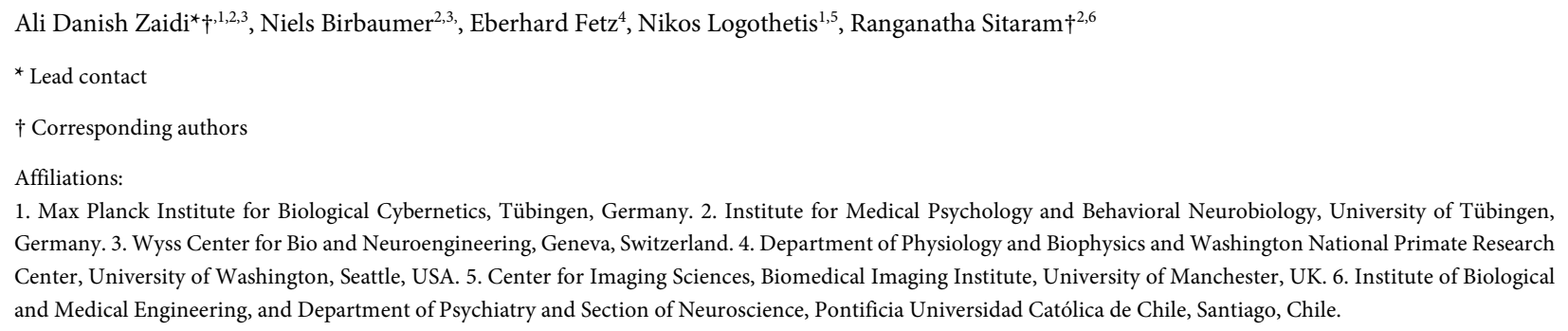

\section{Abstract}

The "initial-dip" is a transient decrease frequently observed in functional neuroimaging signals, immediately after stimulus onset, and is believed to originate from a rise in deoxy-hemoglobin (HbR) caused by local neural activity. It has been shown to be more spatially specific than the hemodynamic response, and is believed to represent focal neuronal activity. However, despite being observed in various neuroimaging modalities (such as fMRI, fNIRS, etc), its origins are disputed and its neuronal correlates unknown. Here, we show that the initial-dip is dominated by a decrease in total-hemoglobin (HbT). We also find a biphasic response in $\mathrm{HbR}$, with an early decrease and later rebound. However, HbT decreases were always large enough to counter spiking-induced increases in HbR. Moreover, the HbT-dip and HbR-rebound were strongly coupled to highly localized spiking activity. Our results suggest that the HbT-dip helps prevent accumulation of spiking-induced HbRconcentration in capillaries by flushing out $\mathrm{HbT}$, probably by active venule dilation.

\section{Introduction}

Functional neuroimaging is a powerful non-invasive tool for studying brain function in health and disease, that uses changes in blood oxygenation as a proxy for estimating local neuronal activity [1]. However, which feature of the hemodynamic signal best reflects local neuronal activity remains an open question. The most commonly used feature is the hemodynamic response amplitude, which is slow and unspecific[1]. Since neuronal processes such as multi-unit spiking are fast, dynamic and spatially localized, a feature in the BOLD signal with similar properties, which also correlates strongly with local neuronal activity, would be an ideal candidate. Early fMRI studies reported such a quick and localized dip in the initial BOLD signal immediately following stimulus onset in various brain areas[2], [3]. This early decrease was termed the 'initial-dip', and was believed to originate from a rise in deoxy-hemoglobin (HbR) caused by stimulus-induced changes in localized neuronal activity[2]. Supporting evidence comes from studies reporting spatially localized dips in tissue partial oxygen pressure[4], [5], and increases in the concentration of HbR [6], observed at the time of the dip. The initial-dip is also more spatially localized than the positive BOLD response [7], and has been used to accurately map orientation columns in the visual cortex (better than the positive-response)[8]. Based on these observations, the initial-dip is believed to represent focal neuronal activity [8]. Although the initial-dip has been observed in various 
functional neuroimaging modalities (such as BOLD-fMRI [2], [7], [9], optical imaging [10], [11], fNIRS[12] and pO ${ }_{2}$-measurements [4]), its origins are disputed [11] and its precise neuronal correlates are all but entirely unknown.

We recently documented a method for the simultaneous acquisition of epidural fNIRS and intra-cortical electrophysiology in primates (Fig. 1A-B), demonstrating that fNIRS has high SNR when acquired epidurally[12], making it ideal for studying local neuro-vascular interactions. FNIRS uses a light-emitter and detector pair (optode pair) to measure changes in concentrations of oxygenated $(\mathrm{HbO})$, deoxygenated $(\mathrm{HbR})$ and total $(\mathrm{HbT})$ hemoglobin, within the vascular compartments in a small volume of tissue[13], [14]. We recorded runs of both spontaneous and stimulus-induced activity in the primary visual cortex of two anesthetized monkeys.

\section{Results}

Fig. 1C shows the traces of $\mathrm{HbO}, \mathrm{HbR}, \mathrm{HbT}$ and multi-unit spike-rates for an example run with visual stimulation, consisting of 20 trials. The grey bars mark the $5 \mathrm{~s}$ of visual stimulation (whole-field rotating chequerboard with high contrast), which were followed by 15 seconds of rest (white spaces). Obvious dips in the HbO signals can be observed on some trials (black arrows). The average traces of these 20 trials elicited observable dips in both $\mathrm{HbO}$ and $\mathrm{HbT}$ (Fig. 1D). We used the mean signal slope between 0 and 1s as a metric of the 'strength' of the initial-dip for each hemodynamic signal, and found that both the HbO and HbT traces had significant dips (Fig. 1E). Similarly, in the mean traces of all 260 trials from our dataset, a clear dip in the HbO and HbT signals can be observed, without any changes in HbR (Fig. 1F-G, Table 1).

To understand the relationship between neuronal activity and the initial-dip, we divided the 260 trials in our dataset into two groups based on the peak spike-rate during stimulus onset, namely, high-spiking trials (899.96 $\pm 12.89 \mathrm{spk} / \mathrm{s} ; \mathrm{n}=122)$ and lowspiking trials (497.28 $\pm 8.35 \mathrm{spk} / \mathrm{s} ; \mathrm{n}=125)$ (Fig. 2A). For high-spiking trials we observed strong dips in HbO, HbR and HbT traces. Although the overall distribution of dips in $\mathrm{HbO}$ and $\mathrm{HbT}$ were not significantly different ( $\mathrm{p}>0.32$; Wilcoxon's rank-sum test), a trial-by-trial comparison revealed that $\mathrm{HbT}$ dips were in fact larger ( $\mathrm{p}<10^{-5}$, Wilcoxon's signed-rank test; Fig. 2B-C). Although lowspiking trials seem to elicit faint modulations in the $\mathrm{HbO}$ and $\mathrm{HbT}$ signals, we did not observe significant changes in their corresponding slopes ( $<<0.1$; Fig. 2C). The low-spiking trials themselves, however, had both significantly high peak spike-rates, and strong stimulus-induced spike-rate modulations (Fig. 2D). Furthermore, in high-spiking trials, we observed a biphasic response in the slope of HbR traces, which was absent in the low-spiking trials (Fig. 2E). The HbR elicited a small but significant dip (between 0-0.75s, epoch I) and a later rebound in the high spiking trials (defined as mean HbR slope between 0.75-1.75s, epoch II, Fig. 2F). This illustrates that there is indeed an increase in HbR signal with higher spiking activity.

We next assessed the relationship of the initial-dip with various bands of the local field potential (LFP). We filtered the extracellular field potential into eight frequency bands, namely the DeltaTheta (1-8 Hz), Alpha (9-15 Hz), Spindle (15-20 Hz), lowGamma (lGam, 20-40 Hz), Gamma (Gam, 40-60 Hz), high-Gamma (hGam, 60-100 Hz), very high-Gamma (vGam, 125-300 Hz) and multi-unit activity (MUA, 1-3 kHz) bands, and obtained their respective band envelopes (see Methods for details). From the various LFP bands we analyzed, only peaks in high-frequency bands had a significant correlation with the HbO and $\mathrm{HbT}$ dips (Fig. 2G). However, the strongest dependence was still observed with peaks in spiking activity for both $\mathrm{HbO}$ and $\mathrm{HbT}$ dips, with slightly 
higher correlations observed with $\mathrm{HbT}$ than $\mathrm{HbO}$ (Fig. 2G, Fig. S1). We next determined how this relationship with spiking varied as a function of distance over cortical surface. We obtained the correlations between the HbT dip and the peak spike-rates on the three tetrodes placed between the emitter and detector. We found that the correlation was strongest with the tetrode closest to the emitter, and that it decreased with increasing distance from the emitter $\left(\mathrm{r}=-0.94 ; \mathrm{p}<10^{-4}\right.$, Fig. 2H). The results were identical when we used the peak-amplitude of the initial-dip instead of the mean signal slope for both HbO and HbT dips (Fig. S2). This finding not only corroborates the idea that the initial-dip is a spatially localized hemodynamic response, but also provides neurovascular evidence that fNIRS has a spatial sampling bias in favor of the emitter, questioning the popular "banana model" that assumes uniform sampling through the volume of tissue between the emitter and detector[13].

It might be argued that stimulus induced activity introduces artificial correlations between the neuronal and hemodynamic responses, by inducing highly synchronous spatio-temporal patterns [15]. To ensure our results didn't arise from such correlations, we analyzed recordings of spontaneous ongoing activity in the absence of visual stimulation, where the monkeys' eyes were closed and covered with thick gauze. Fig. 3A shows traces of $\mathrm{HbO}, \mathrm{HbR}, \mathrm{HbT}$ and spike-rates for an example run of spontaneous activity, consisting of 15 minutes. Dips in the $\mathrm{HbO}$ and $\mathrm{HbT}$ signals can be seen to coincide with strong bursts in spiking activity (Fig. 3A, arrows and bars). To analyze the relationship between spiking and hemodynamic signals, we used system identification to estimate the impulse response from spiking to $\mathrm{HbO}, \mathrm{HbR}$ and $\mathrm{HbT}$ traces. This method uses the Wiener-Hopf relationship [16] to estimate the impulse-response to a unit-pulse ( $1 \mathrm{SDU}$ amplitude, $1 \mathrm{~s}$ duration at $\mathrm{t}=0$ ) from the input (spiking activity) on the output (hemodynamic signal), and is independent of the shape and auto-correlation structure of the input. Fig. 3B shows the mean impulse-responses from spiking on $\mathrm{HbO}, \mathrm{HbR}$ and $\mathrm{HbT}$ traces. There is an evident dip in the $\mathrm{HbO}$ and $\mathrm{HbT}$ traces. However, the slopes of these impulse response functions provide a clearer picture of the signal dynamics (Fig. 3C), where a decrease in $\mathrm{HbO}$ and HbT can be observed at $\mathrm{t}=1$ s (Fig. 3D; $\mathrm{n}=48$; $\check{\mathbf{S}}$ ), and a late rebound of $\mathrm{HbR}$ can be observed at $\mathrm{t}=2 \mathrm{~s}$. We next used the total spike count in each run to separate the runs into high-spiking and low-spiking runs (Fig. 3E). Fig. 3F shows the impulse-responses obtained for the high-spiking (thick) and low-spiking (thin) runs. The slopes of the impulse-responses show that the high-spiking trials had large, significant dips for all three hemodynamic signals (HbO, HbR and HbT; Fig. 3G-H). Furthermore, we found no significant difference between the overall distributions of $\mathrm{HbO}$ and HbT dips ( $\mathrm{p}>0.45, \mathrm{n}=85$, Wilcoxon's rank-sum test). However, on trial-by-trial comparison, HbT dips were significantly stronger than HbO-dips (Fig. 3H; p $<10^{-4}$, n=85, Wilcoxon's one-tailed signed-rank test). Interestingly, although the low spiking runs seemed to elicit dips as well, they did not reach significance. Furthermore, only the high-spiking runs elicited significant modulations in HbR with both significant dips at $\mathrm{t}=1 \mathrm{~s}$ and rebounds at $\mathrm{t}=2 \mathrm{~s}$ (Fig. 3I). These results are identical to those obtained from the analysis of stimulus induced activity, and are thus independent of the visual stimulation paradigm.

In the analysis of both spontaneous and stimulus-induced activity, we find that the initial-dip is dominated by a decrease in $\mathrm{HbT}$, in trials with strong bursts in spike-rates. However, it might be argued that this decrease in $\mathrm{HbT}$ is not an actual change in blood volume, but a consequence arising from signal trends, such as the slope of the hemodynamic signal before stimulus onset, or the choice of analytical parameters, such as the differential path-length factors (DPFs) used for the conversion of optical density to concentration changes (the only parameter-dependent transformation in the analysis). Surprisingly, the strength of the initial-dip 
failed to correlate with the mean slope of the hemodynamic signal $0-2 \mathrm{~s}$ prior to stimulus onset $(\mathrm{r}=-0.002, \mathrm{p}>0.9$, Pearson's correlation coefficient of correlation), suggesting that the trend of the hemodynamic signal before the dip fails to affect the initialdip. We also used various combinations of physiologically relevant DPFs, as reported earlier[6], in the estimation of concentration changes in $\mathrm{HbO}, \mathrm{HbR}$ and HbT, and obtained identical results (see Fig. S3). To be sure, we also analyzed the raw optical density changes for both wavelengths $(760 \mathrm{~nm}$ and $850 \mathrm{~nm})$. We found a significant decrease in the optical densities for both chromophores, which was enhanced in high-spiking trials (see Fig. S4). The decrease in chromophore concentration at both wavelengths can only be attributed to decreases in total hemoglobin concentration (HbT). Furthermore, within trials with low spiking activity, even though we do not see significant changes in the slope of the $\mathrm{HbO}$ and $\mathrm{HbR}$ signals, we do find small but significant changes in their concentration (see Fig. S5). We detected significant increases in the HbR concentration (mean HbR concentration change between 0 to $0.8 \mathrm{~s}, \mathrm{p}<0.05$, Wilcoxon's signed-rank test) as well as significant decreases in the HbO concentration (see Fig. S5C, $\mathrm{p}<0.05$; $\mathrm{n}=125$; Wilcoxon's sign-rank test) but failed to detect significant changes in $\mathrm{HbT}$ ( $\mathrm{p}>0.1, \mathrm{n}=125$; Wilcoxon's signed rank test), an observation that is in agreement with previous reports on the initial-dip [6], [17]. Finally, the trials within the lowest quartile of spike-rates elicited neither initial-dips (in $\mathrm{HbO}, \mathrm{HbR}$ or $\mathrm{HbT}$ traces, mean slope between 0-1s), nor changes in concentration (mean concentration change between 0 -1s), even though these trials still had significantly high bursts in spike rates (peak rate $300 \pm 40$ spk/s; $<<10^{-11} ; \mathrm{n}=59$, Wilcoxon's signed-rank test). These observations demonstrate two different manifestations of the initial-dip. During low-spiking, there is an oxymetric change consisting of an increase in HbR and decrease in HbO concentration. During very high spiking, there is a volumetric change, consisting of a decrease in $\mathrm{HbT}$ (and consequently $\mathrm{HbO}$ and $\mathrm{HbR}$ ).

Interestingly, all significant dips detected in optical density traces also translated to changes in hemoglobin concentration, irrespective of the choice of parameters used for converting optical density to concentration change (see Fig. S3). Combined with previous studies [6], these results are in conflict with an earlier report where changes in optical density failed to translate to changes in $\mathrm{HbO}, \mathrm{HbR}$ or HbT signals[11].

\section{Discussion}

Although the exact vascular compartments that fNIRS samples from have not yet been firmly established, it is generally believed to reflect oxymetric changes within vessels smaller than $1 \mathrm{~mm}$ in diameter[14], such as pre-capillary arterioles, capillaries and postcapillary venules (Capillary and Peri-capillary Vessels, henceforth CPVs), which is where most of the oxygen-exchange occurs[18], and hence where the largest changes in blood oxygenation occur. This is exemplified by the increase in $\mathrm{HbO}$ and decrease in $\mathrm{HbR}$ observed during influx of oxy-saturated blood into CPVs during the positive hemodynamic response (Fig. 1F). Thus, even though neuronal activity leads to an increase in $\mathrm{HbR}$ concentration, the HbR signal during the positive response decreases, once oxysaturated blood passes through the CPVs post arteriole dilation. Even the transient increases observed in the HbR signal during the dip only last until the HbT response commences. Hence, a decrease in both $\mathrm{HbO}$ and HbR during the initial-dip most likely represents decreases in the blood-volume within CPVs. In our data, the $\mathrm{HbO} / \mathrm{HbT}$ dip ratio (the ratio of $\mathrm{HbO}$ to $\mathrm{HbT}$ decrease at maximal dip) is $50.4 \pm 17 \%$ (mean \pm sem) for stimulus-induced, and $58.9 \% \pm 32 \%$ for spontaneous activity, which is within the range of oxygen saturation reported within CPVs [18]. A possible means to attain a decrease in CPV blood volume would be through the dilation of post-capillary venules. Post-capillary venules have recently been shown to have band-like smooth muscles encircling 
their circumference, similar to those associated with precapillary arterioles [19]. Furthermore, small venules have been shown to increase their diameter simultaneously with strong arteriolar dilations in recordings of spontaneous activity [20]. However, since the primary arterioles that are dilated are further away from the capillaries, the influx of blood takes longer to reach the capillaries. Therefore, upon post-capillary venule dilation, the decrease in capillary blood pressure would briefly compress the capillary, flushing the blood out, before the influx of oxygenated blood caused by arteriole dilation. Recently, erythrocytes have been reported to deform with reduced oxygen tension, facilitating an increase in their flow-rate through the capillary lumen[21], aiding this process. Indeed, a transient increase in capillary RBC velocity can be observed immediately after stimulus onset, which briefly subsides, before finally increasing again (see figures $4 \mathrm{~B}$ and $4 \mathrm{D}$ in 20 ).

Such a flushing of CPV blood could serve to prevent HbR accumulation in the capillaries, enforcing a virtual "upper-limit" of $\mathrm{HbR}$ concentration in the vascular tissue, as well as facilitating the influx of oxygen saturated blood from the arterioles. Indeed, in our data, we found that spiking correlated strongly with the HbR-rebound (Fig. 4A). However, the HbT dips were consistently larger than the HbR-rebounds, maintaining an upper-limit of HbR concentration, and hence no relationship was observed between spiking and HbR concentration change between 0.75-1.75s (Fig. 4B). Moreover, when corrected for the HbT dip (by subtracting HbT traces from HbR traces), the "dip-corrected" HbR traces reveal increases in concentration that are correlated to spiking activity (Fig. 4C). In contrast, no such relationship is observed with "dip-corrected” HbO traces (Fig. 4D), illustrating that the initial-dip counters rising $\mathrm{HbR}$ concentration in the vascular tissue. This deoxygenated blood flushed from individual CPVs would flow into the surface venules, transiently increasing their HbR concentration. Indeed, cortical-depth resolved BOLD-fMRI, believed to reflect changes in tissue HbR [1], [22], reveals that the amplitude of the initial-dip is largest near the cortical surface, in both human [9] and animal [10] studies. Further experiments quantifying changes in $\mathrm{HbO}$ and $\mathrm{HbR}$ in the various vascular compartments could shed further light on the exact vascular mechanisms of the initial-dip. Nevertheless, our results conclusively demonstrate that the initial-dips in both $\mathrm{HbO}$ and $\mathrm{HbT}$ traces are strongly correlated with highly localized spiking activity. Furthermore, since we find no relationships between the initial-dip and low-frequency LFP activity, it establishes that the initial-dip is a highly specific marker of localized bursts in spiking activity.

Although we recorded signals from anesthetized monkeys, it has been shown that this anesthesia regime does not significantly alter local neuro-vascular coupling [23]. We also find that fNIRS represents focal neuro-vascular changes close to the emitter, challenging the generally accepted "banana" model that assumes the cortical volume sampled by fNIRS to be uniformly distributed between the emitter and detector [14]. Concurrently, a study comparing simultaneously recorded fNIRS and fMRI signals in humans finds that the voxels correlating best with $\mathrm{HbO} / \mathrm{HbR}$ changes are consistently closer to the emitter (see Fig. 2 and Table 2 in [24]), though this is not explicitly stated in their results. Overall these results shed further light on the neuro-vascular changes underlying the initial-dip, and enable a better interpretation of functional neuroimaging signals.

In conclusion, we show that the initial dip, though present in both $\mathrm{HbO}$ and $\mathrm{HbT}$ signals, is dominated by $\mathrm{HbT}$ changes that are correlated to highly-localized spiking, demonstrating that these changes are specific to excitatory neuronal activity. This study is, to the best of our knowledge, the first report of an exclusive marker of spiking activity in hemodynamic signals. 


\section{Abbreviations}

BOLD: blood-oxygen level dependent signal

CPVs: Capillary and Peri-capillary Vessels (precapillary-arterioles, capillaries and post-capillary venules)

fMRI: functional Magnetic Resonance Imaging

fNIRS: functional Near Infra-Red Spectroscopy

HbO: concentration of oxy-hemoglobin

HbR: concentration of deoxy-hemoglobin

$\mathrm{HbT}$ : concentration of total hemoglobin

LFP: local field potential

R: Wilcoxon's one-tailed rank-sum test

Š: Wilcoxon's two-tailed signed rank test

$\mathrm{T}_{1}$ : Tetrode $1(0.55 \mathrm{~mm}$ from emitter)

$\mathrm{T}_{2}$ : Tetrode 2 (1.75mm from emitter)

$\mathrm{T}_{3}$ : Tetrode 2 (2.95mm from emitter)

\section{Acknowledgements}

We would like to thank Matthias Munk, Cristina Risueno and Rebekka Bernard for help during the collection of data, and Mirsat Memej and Eduard Krampe for their help during the design and construction of the recording system, and Vishal Kapoor and Mastaka Watanabe for feedback on an earlier version of the manuscript. We acknowledge funding from the DFG, CIN and Max-Planck Society.

\section{References}

[1] N. K. Logothetis, "What we can do and what we cannot do with fMRI.," Nature, vol. 453, no. 7197, pp. 869-878, 2008.

[2] X. Hu and E. Yacoub, "The story of the initial dip in fMRI," Neuroimage, vol. 62, no. 2, pp. 1103-1108, 2012.

[3] E. Yacoub and X. Hu, "Detection of the Early Decrease in fMRI in the Motor Area," vol. 441, no. 1999, p. 55455, 2000.

[4] A. Parpaleix, Y. G. Houssen, and S. Charpak, "Imaging local neuronal activity by monitoring PO2 transients in capillaries," Nat. Med., vol. 19, no. 2, pp. 241-246, Jan. 2013.

[5] C. Zhang, S. Belanger, P. Pouliot, and F. Lesage, "Measurement of local partial pressure of oxygen in the brain tissue under normoxia and epilepsy with phosphorescence lifetime microscopy," PLoS One, vol. 10, no. 8, pp. 1-14, 2015.

[6] G. Jasdzewski, G. Strangman, J. Wagner, K. K. Kwong, R. A. Poldrack, and D. A. Boas, "Differences in the hemodynamic response to event-related motor and visual paradigms as measured by near-infrared spectroscopy,” Neuroimage, vol. 20, no. 1, pp. 479-488, 2003.

[7] M. Watanabe, A. Bartels, J. H. Macke, Y. Murayama, and N. K. Logothetis, "Temporal Jitter of the BOLD Signal Reveals a Reliable Initial Dip and Improved Spatial Resolution,” Curr. Biol., vol. 23, no. 21, pp. 2146-2150, 2013.

[8] D. S. Kim, T. Q. Duong, and S. G. Kim, "High-resolution mapping of iso-orientation columns by fMRI.," Nat. Neurosci., vol. 3, no. 2, pp. 164-169, 2000.

[9] J. C. W. Siero, J. Hendrikse, H. Hoogduin, N. Petridou, P. Luijten, and M. J. Donahue, "Cortical depth dependence of the BOLD initial dip and poststimulus undershoot in human visual cortex at 7 Tesla.,” Magn. Reson. Med., vol. 73, no. 6, pp. 2283-95, Jun. 2015.

[10] P. Tian et al., "Cortical depth-specific microvascular dilation underlies laminar differences in blood oxygenation level-dependent functional MRI signal.,” Proc. Natl. Acad. Sci. U. S. A., vol. 107, no. 34, pp. 15246-15251, Aug. 2010.

[11] Y. B. Sirotin, E. M. C. Hillman, C. Bordier, and A. Das, "Spatiotemporal precision and hemodynamic mechanism of optical point spreads in alert primates.,” Proc. Natl. Acad. Sci. U. S. A., vol. 106, no. 43, pp. 18390-18395, 2009.

[12] A. D. Zaidi et al., "Simultaneous epidural functional near-infrared spectroscopy and cortical electrophysiology as a tool for studying local neurovascular coupling in primates," Neuroimage, vol. 120, pp. 394-399, 2015.

[13] A. Villringer, "Non-invasive optical spectroscopy and imaging of human brain function," Trends Neurosci., vol. 20, no. 10, pp. 435-442, Oct. 1997.

[14] M. Ferrari and V. Quaresima, "A brief review on the history of human functional near-infrared spectroscopy (fNIRS) development and fields of application,” Neuroimage, vol. 63, no. 2, pp. 921-935, 2012. 
[15] N. K. Logothetis, J. Pauls, M. Augath, T. Trinath, and a Oeltermann, "Neurophysiological investigation of the basis of the fMRI signal.," Nature, vol. 412, no. 6843, pp. 150-157, 2001.

[16] K. J. Keesman, System identification: an introduction. Springer Science \& Business Media, 2011.

[17] C. Martin, J. Martindale, J. Berwick, and J. Mayhew, "Investigating neural-hemodynamic coupling and the hemodynamic response function in the awake rat," Neuroimage, vol. 32, no. 1, pp. 33-48, 2006.

[18] S. Sakadžić et al., "Large arteriolar component of oxygen delivery implies a safe margin of oxygen supply to cerebral tissue," Nat. Commun., vol. 5, p. 5734, 2014.

[19] R. A. Hill, L. Tong, P. Yuan, S. Murikinati, S. Gupta, and J. Grutzendler, "Regional Blood Flow in the Normal and Ischemic Brain Is Controlled by Arteriolar Smooth Muscle Cell Contractility and Not by Capillary Pericytes," Neuron, vol. 87, no. 1, pp. 95-110, 2015.

[20] P. J. Drew, A. Y. Shih, and D. Kleinfeld, "Fluctuating and sensory-induced vasodynamics in rodent cortex extend arteriole capacity.," Proc. Natl. Acad. Sci. U. S. A., vol. 108, no. 20, pp. 8473-8478, May 2011.

[21] H. Wei et al., "Erythrocytes Are Oxygen-Sensing Regulators of the Cerebral Microcirculation," Neuron, vol. 91, no. 4, pp. 851-862, Aug. 2016.

[22] S. A. Huettel, A. W. Song, and G. McCarthy, Functional magnetic resonance imaging. 2014.

[23] J. B. M. Goense and N. K. Logothetis, "Neurophysiology of the BOLD fMRI Signal in Awake Monkeys," Curr. Biol., vol. 18, no. 9, pp. 631-640, 2008.

[24] X. Cui, S. Bray, D. M. Bryant, G. H. Glover, and A. L. Reiss, "A quantitative comparison of NIRS and fMRI across multiple cognitive tasks," Neuroimage, vol. 54, no. 4, pp. 2808-2821, 2011.

\section{Methods}

\section{Surgery and craniotomy}

Two healthy adult monkeys, M1 (female; $8 \mathrm{~kg}$ ) and M2 (male; $10 \mathrm{~kg}$ ), were used for the experiments. All vital parameters were monitored during anesthesia. After sedation of the animals using ketamine $(15 \mathrm{mg} / \mathrm{kg})$, anesthesia was initiated with fentanyl (31 $\mu \mathrm{g} / \mathrm{kg})$, thiopental $(5 \mathrm{mg} / \mathrm{kg})$, and succinylcholine chloride ( $3 \mathrm{mg} / \mathrm{kg}$ ), and then the animals were intubated and ventilated. A Servo Ventilator 900C (Siemens, Germany) was used for ventilation, with respiration parameters adjusted to each animal's age and weight. Anesthesia was maintained using remifentanil $(0.2-1 \mu \mathrm{g} / \mathrm{kg} / \mathrm{min})$ and mivacurium chloride (4-7 mg/kg/h). An iso-osmotic solution (Jonosteril, Fresenius Kabi, Germany) was infused at a rate of $10 \mathrm{ml} / \mathrm{kg} / \mathrm{h}$. During the entire experiment, each animal's body temperature was maintained between $38.5^{\circ} \mathrm{C}$ and $39.5^{\circ} \mathrm{C}$, and $\mathrm{SpO} 2$ was maintained above $95 \%$. Under anesthesia, a craniotomy was made on the left hemisphere of the skull to access the primary visual cortex. During each experiment, the bone was removed to create a rectangular slit measuring $3 \mathrm{~mm}$ anterio-posteriorly and $20 \mathrm{~mm}$ medio-laterally, exposing the dura. Connective tissue, if present above the dura, was carefully removed. For each monkey, at least two weeks were allowed to pass between successive experiments. All protocols were approved by the local authorities (Regierungspräsidium, Tübingen) and are in agreement with European guidelines for the ethical treatment of laboratory animals.

\section{Near-infrared Spectroscopy}

We used a NIRScout machine purchased from NIRx Medizintechnik GmbH, Berlin. The system performs dual wavelength LED light-based spectroscopic measurements. The wavelengths used were $760 \mathrm{~nm}$ and $850 \mathrm{~nm}$, with a maximum of $5 \mu \mathrm{W}$ effective power at the emitter end. Sampling was performed at $20 \mathrm{~Hz}$. We used modified emitters and detectors, and optical fiber bundles for sending the light from the LED source into the tissue, and also for detecting refracted light from the tissue. The fiber bundles were ordered from NIRx Medizintechnik GmbH, Berlin, Germany. Both the emitter and detector fiber bundles had iron ferrule tips with an aperture of $2.5 \mathrm{~mm}$ on the ends that touched the dura. We used three optodes in a linear arrangement separated by $6 \mathrm{~mm}$ each. Three tetrodes and single-wire electrodes each were added between each pair of adjacent optodes. We used the central optode as a constant detector, and alternated the peripheral optodes during sessions, such that on a given experimental day, $50 \%$ of data came from one emitter-detector pair and 50\% from the other. The recording instrument was connected via USB to a laptop computer running an interactive software called NIRStar provided along with the instrument. The software was used for starting and stopping recordings, and also for setting up the various parameters, such as, the number of sources and detectors, and the sampling rate. The instrument 
received TTL pulses from the stimulus system and the electrophysiological recording system, for synchronization purposes. The system sent $1 \mathrm{~ms}$ TTL pulses every $50 \mathrm{~ms}$ to the recording system that corresponded to light pulses.

Custom built tetrodes and electrodes were used. All tetrodes and single electrodes had impedance values less than $1 \mathrm{M} \Omega$. The impedance of each channel was noted before loading the tetrodes on to the drive, and once again while unloading the tetrode after the experiment, to ensure that the contacts were intact throughout the duration of the experiment. To drive the electrodes into the brain a 64-channel Eckhorn matrix was used (Thomas Recording GmbH, Giessen, Germany). The electrodes were loaded in guide tubes a day before the experiment. On the day of the experiment, the tetrodes were driven using a software interface provided by Thomas Recording GmbH, Giessen, Germany. The output was connected to a speaker and an oscilloscope, with a switch to help cycle between different channels. We advanced electrodes into the cortex one by one until we heard a reliable population response to a rotating checkerboard flickering at $0.5 \mathrm{~Hz}$.

\section{Spontaneous activity}

For each run, spontaneous activity was recorded for 15 minutes, in the absence of visual stimulation. The eyes of the monkey were closed and thick cotton gauze was used to cover the eyelids. Visual stimulation A fundus camera was used to locate the fovea for each eye. For presenting visual stimulation, a fiber optic system (Avotec, Silent Vision, USA) was positioned in front of each eye, so as to be centered on the fovea. To adjust the plane of focus, contact lenses (hard PMMA lenses, Wöhlk, Kiel, Germany) were inserted to the monkey's eyes. We used whole-field, rotating chequerboard to drive the neural activity. The direction of rotation was reversed every second. Each trial consisted of 5 seconds of visual stimulation followed by 15 seconds of a dark screen. A single run consisted of 20 trials. Data presented are from 13 runs spread over 8 experimental days.

All analyses were performed in MATLAB using custom written code. Only runs that cleared visual screening for artifacts were used. Data points that were larger than 5 SDU were excluded from the analysis, so as to avoid tail-effects for correlation analysis. Normality for each distribution was confirmed before analysis was performed.

The raw wavelength absorption data from the NIRS system was converted to concentration changes of [HbO] and [HbR] using a modified Beer-

Lambert equation $(\mathrm{DPF}=6,6)$. For correlating hemodynamic signals with neural activity, the signals were filtered between 0.01 and $1 \mathrm{~Hz}$ to remove any low frequency drifts. For a trial-by-trial analysis, the hemodynamic response for each trial was zero-corrected by subtracting, from each hemodynamic response, the value at the start of the trial.

Electrophysiological signal processing

The extracellular field potential signal was recorded at $20.8333 \mathrm{kHz}$ and digitized using a 16-bit AD converted. From the raw signal, eight frequency bands (namely, DeltaTheta (1-8 Hz), Alpha (9-15 Hz), Spindle (15-20 Hz), low Gamma (20-40 Hz), Gamma (40-60 Hz), high Gamma (60-120 Hz), very high Gamma $(120-250 \mathrm{~Hz})$ and MUA $(1-3 \mathrm{kHz}))$ were band-pass filtered using a $10^{\text {th }}$ order Butterworth filter. The envelope for each band was then obtained by taking the absolute value of the Hilbert transform of the filtered signal. The band-envelope was then converted to standard deviation units by subtracting the mean and dividing by the standard deviation of the signal. This signal was then resampled at $20 \mathrm{~Hz}$, to allow comparisons with hemodynamic signals. Spike rates were obtained by detecting peaks in the MUA signal larger than a threshold (2 SDU), and by counting the threshold-crossing events in $50 \mathrm{~ms}$ bins. Varying the detection threshold between 2, 3 or 4 SDU did not affect the results. System identification based impulse response estimation in spontaneous activity 
Each hemodynamic signal was first filtered between 0.01 to $1 \mathrm{~Hz}$ and then normalized by subtracting the mean and dividing by the standard deviation. Spike-counts were obtained by counting the number of threshold crosses ( $>3 \mathrm{SDU}$ ) in the $1-3 \mathrm{kHz}$ band in $50 \mathrm{~ms}$ bins. The bin-count was signals were then decimated to $1 \mathrm{~Hz}$ to enable processing with the toolbox.

299 For estimating the impulse response function for each epoch, the spike-rate for that epoch was used as the input and the hemodynamic signal as 300 output.

\section{Calculation of modulation indices}

The 'On' epoch for each trial was defined as the time from 0 to 5.05 seconds. The extra $0.05 \mathrm{~s}$ were added to accommodate for the off response. The 'Off' epoch was defined as the time between 5.05 to 10.05 seconds. The modulation index (MI) was then calculated using the formula: neural

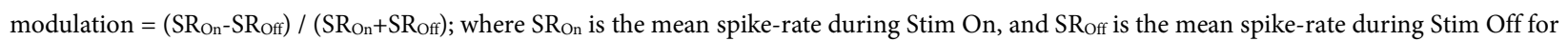
each trial. Runs without significant visual modulation of spike-rates were excluded from the analysis.

$306 \underline{\text { Statistics }}$ All distributions were confirmed to be normally distributed using the Kolmogorov-Smirnov test in Matlab, before using means as a measure of central tendency. All correlation coefficients represent Pearson's correlation coefficient and corresponding significance values. To calculate the correlations, the trials were sorted and divided into 10 bins (with 26 trials per bin). The mean values of each bin were then correlated. This was done to avoid an otherwise large trial-by-trial variation. The results were independent of the number of bins used for correlation analysis (see Fig. S1) 
bioRxiv preprint doi: https://doi.org/10.1101/259895; this version posted February 22, 2018. The copyright holder for this preprint (which was not certified by peer review) is the author/funder, who has granted bioRxiv a license to display the preprint in perpetuity. It is made available under aCC-BY-NC-ND 4.0 International license.

A

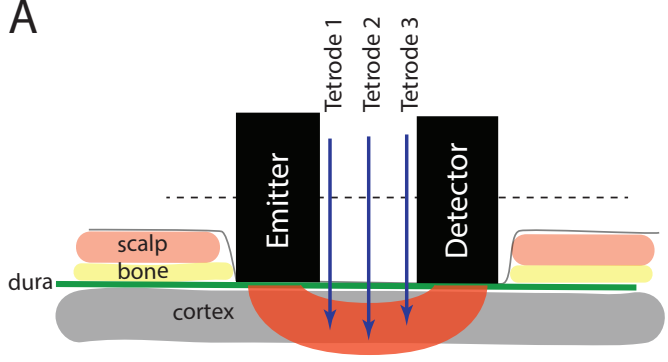

B

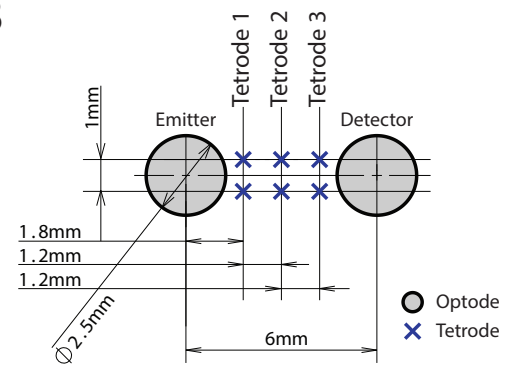

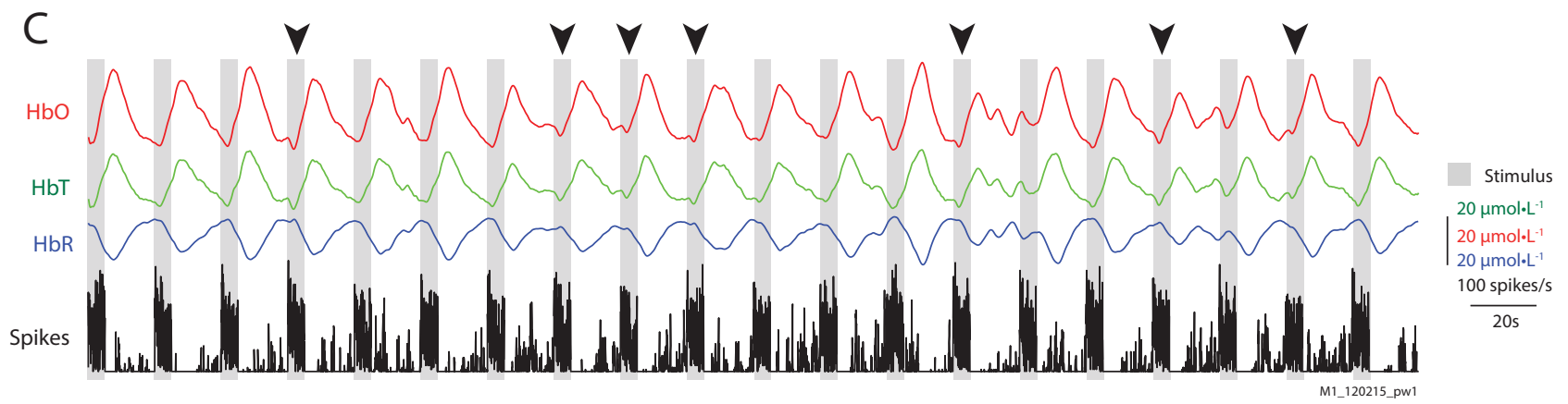

D

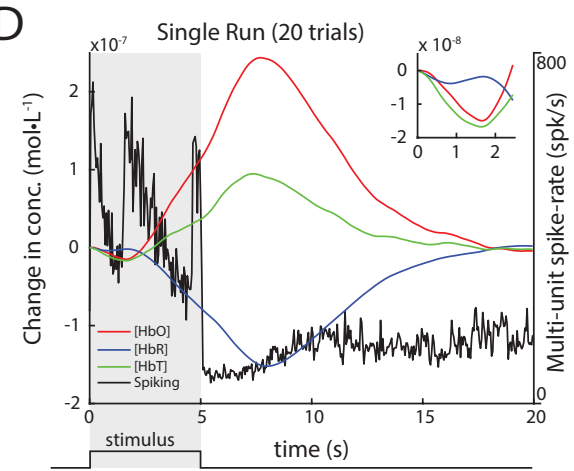

$\mathrm{E}$

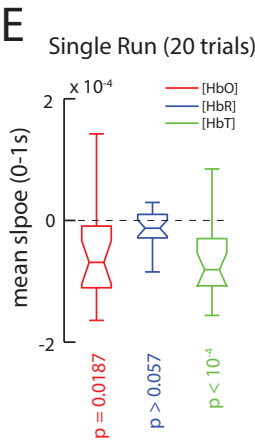

$\mathrm{F}$

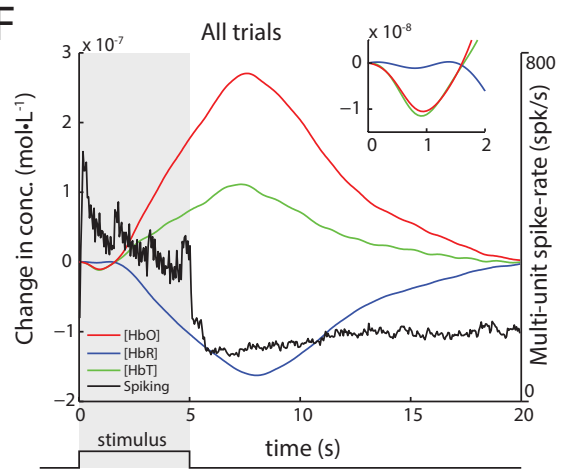

G

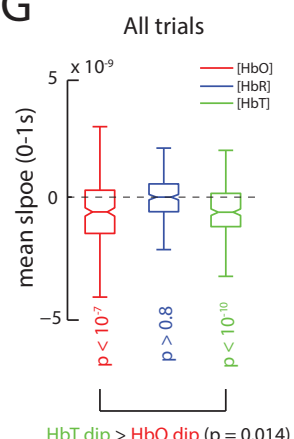

Figure 1. Epidurally measured fNIRS measurements reveal initial dips in hemodynamic signals. A) Illustration of the sensor array with placement of fNIRS optodes and electrodes relative to scalp and brain tissue. B) Transverse section of the sensor array with distances between optodes and electrodes. See methods for details. C) Traces of $\mathrm{HbO}, \mathrm{HbR}$, and Spiking from an example run with 20 trials. Grey bars represent epochs of visual stimulation. Arrows mark trials where initial dips are obvious in signal trends. D) The mean traces of $\mathrm{HbO}, \mathrm{HbR}, \mathrm{HbT}$ and multi-unit spiking (units on the right) for trials shown in (C). Inset) Same hemodynamic traces, but from 0-2.5s. The initial dip is observed in the $\mathrm{HbO}$ and $\mathrm{HbT}$ (inset), but not in the $\mathrm{HbR}$ traces. The shaded region represents visual stimulus presentation. E) Distribution of slopes from 0-1s for $\mathrm{HbO}$, $\mathrm{HbR}$ and $\mathrm{HbT}$ traces for trials in (C). The distributions of $\mathrm{HbO}$ and $\mathrm{HbT}$ slopes are less than zero, but not for those for HbR $\left(\mathrm{p}_{\mathrm{HbO}}=0.0187 ; \mathrm{p}_{\mathrm{HbT}}<10^{-4} ; \mathrm{p}_{\mathrm{HbR}}=0.099 ; n=20 ; \mathrm{S}\right)$. F) The mean traces of $\mathrm{HbO}, \mathrm{HbR}, \mathrm{HbT}$ and multi-unit spiking activity (units on the right) for all trials. Inset) Same hemodynamic traces, but from 0-2s. G) Distribution of signal slopes from 0-1s for $\mathrm{HbO}, \mathrm{HbR}$ and $\mathrm{HbT}$ traces for all trials. The distributions for $\mathrm{HbO}$ and HbT are less than zero, but not for $\mathrm{HbR}\left(\mathrm{p}_{\mathrm{HbO}}<10^{-7} ; \mathrm{p}_{\mathrm{HbT}}<10^{-10} ; \mathrm{p}_{\mathrm{HbR}}>0.1 ; \mathrm{n}=260 ; \mathrm{S}^{\text {) }}\right.$. However, $\mathrm{HbT}$ dips were stronger than $\mathrm{HbO}$ dips $(p=0.028 ; S)$ 
bioRxiv preprint doi: https://doi.org/10.1101/259895; this version posted February 22, 2018. The copyright holder for this preprint (which was not certified by peer review) is the author/funder, who has granted bioRxiv a license to display the preprint in perpetuity. It is made available under aCC-BY-NC-ND 4.0 International license.

A

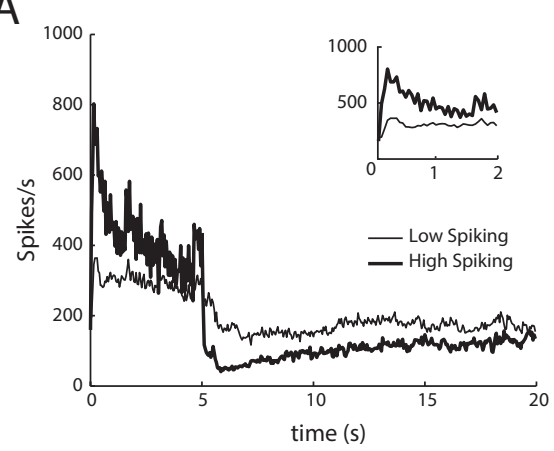

B

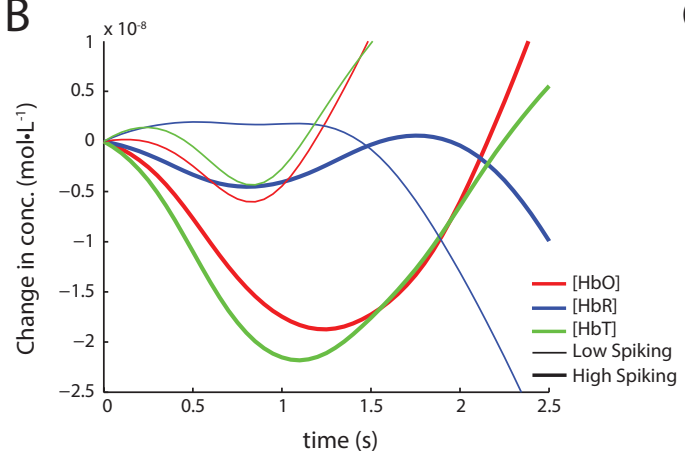

C

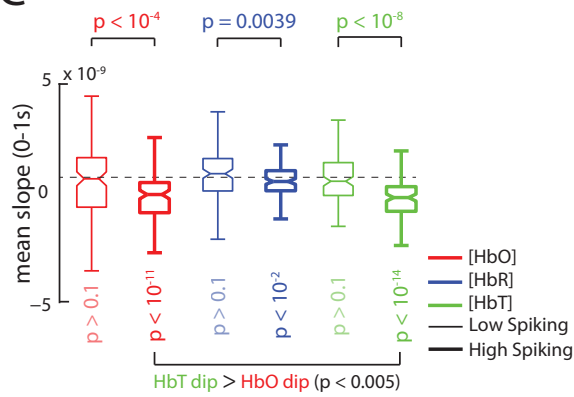

D

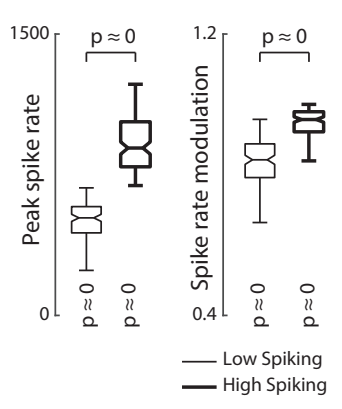

$\mathrm{E}$

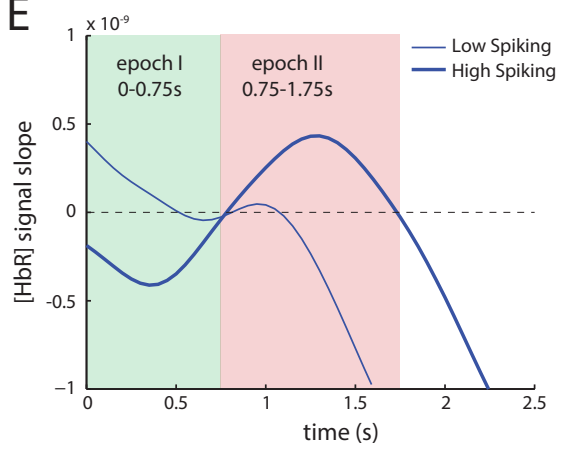

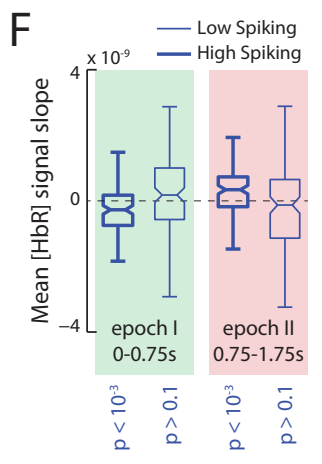

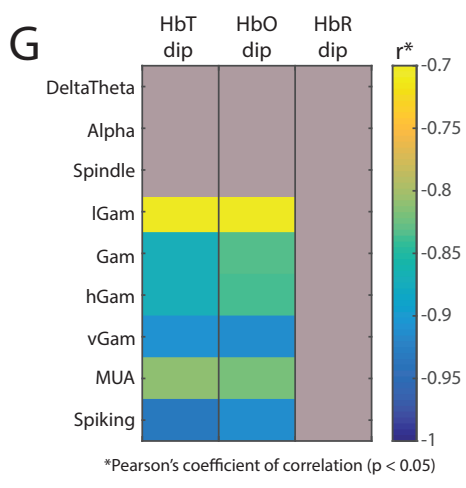

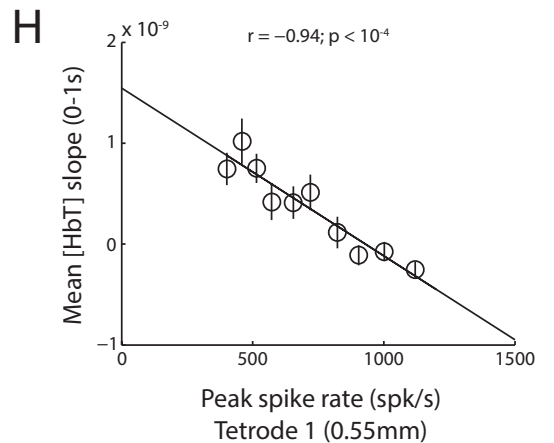
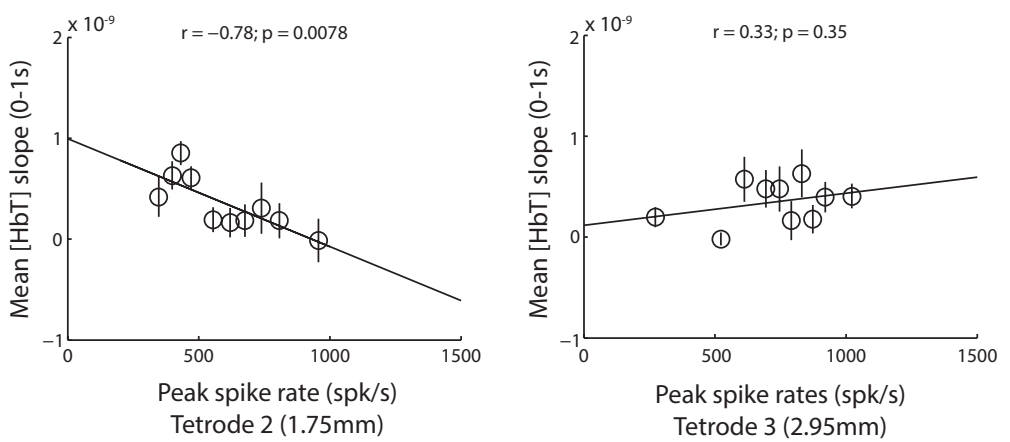

Figure 2. Trials with high spiking activity reveal initial dips comprise of an early HbT decrease, and late HbR increase. A) Mean traces of spike-rates for trials with high and low spiking immediately after stimulus onset (thick and thin traces, respectively). Inset) Same traces, but between 0-2s. B) Mean traces of hemodynamic signals for trials with low (thin) and high spiking as shown in (A). A clear increase in the dips is observed for high spiking trials with the largest dips elicited in $\mathrm{HbT}$ traces. C) Average slopes from 0-1s for $\mathrm{HbO}, \mathrm{HbR}$ and $\mathrm{HbT}$ traces for high (thick) and low (thin) spiking trials. $\mathrm{HbO}, \mathrm{HbR}$ and $\mathrm{HbT}$ all elicit significant dips in high-spiking trials ( $\mathrm{p}_{\mathrm{HbO}}<10^{-11}$; $\left.\mathrm{p}_{\mathrm{HbT}}<10-{ }^{14} ; \mathrm{p}_{\mathrm{HbR}}<10^{-2} ; \mathrm{n}=128 ; \mathrm{S}\right)$, with larger dips in $\mathrm{HbT}$ than $\mathrm{HbO}(\mathrm{p}<0.005 ; \mathrm{n}=125 ;$ pairwise $\mathrm{S})$. Interestingly, trials with low spiking trials do not elicit significant dips in either $\mathrm{HbO}, \mathrm{HbR}$ or $\mathrm{HbT}(p<0.1 ; n=122 ; 5)$. D) Distribution of peak spike-rates and visual modulation of spike-rates for trials with high (thick) and low (thin) peak spike-rates. This illustrates that even though the peak rates were lower in the low-spiking trials, the overall spiking activity was significantly high, as was the visual stimulus induced modulation of spike rates (see Methods for calculation of modulation index). E) Analysis of the slope of HbR traces in high spiking trials reveals a biphasic response, which is almost all but absent in low spiking trials. In high spiking trials (thick trace), an initial negative slope is observed roughly between 0-0.75s (epoch I, shaded green), followed a positive slope roughly between $0.75-1.75 \mathrm{~s}$ (epoch II, shaded red). F) For high spiking trials, the distribution of mean $\mathrm{HbR}$ slopes were significantly negative during epoch I ( $p<10^{-3} ; n=125 ; S$ ), and significantly positive during epoch II ( $\left.p<10^{-3} ; n=125 ; 5\right)$. In contrast, low spiking trials showed no significant modulation of $\mathrm{HbR}$ slopes during either epoch I or II ( $p>0.1 ; n=122 ; \breve{S})$. G) Correlation of mean dips in HbT, HbO and HbR stimulus induced peaks in the power of various LFP frequencies bands and Spiking. Correlations with $p>0.05$ are greyed. Only high frequency bands showed a significant correlation with initial dips, with spiking activity eliciting the strongest relationship, that were marginally higher for $\mathrm{HbT}$ than $\mathrm{HbO}$. H) Strength of the relationship between the HbT dip and spiking activity decreases with distance from the NIRS emitter. Strongest correlations are observed on tetrode closest to emitter $(0.55 \mathrm{~mm}$ away from emitter edge, $1.8 \mathrm{~mm}$ from emitter center), whereas no correlations are observed on tetrode $2.95 \mathrm{~mm}$ away $(4.2 \mathrm{~mm}$ from center). 
bioRxiv preprint doi: https://doi.org/10.1101/259895; this version posted February 22, 2018. The copyright holder for this preprint (which was not certified by peer review) is the author/funder, who has granted bioRxiv a license to display the preprint in perpetuity. It is made available under aCC-BY-NC-ND 4.0 International license.
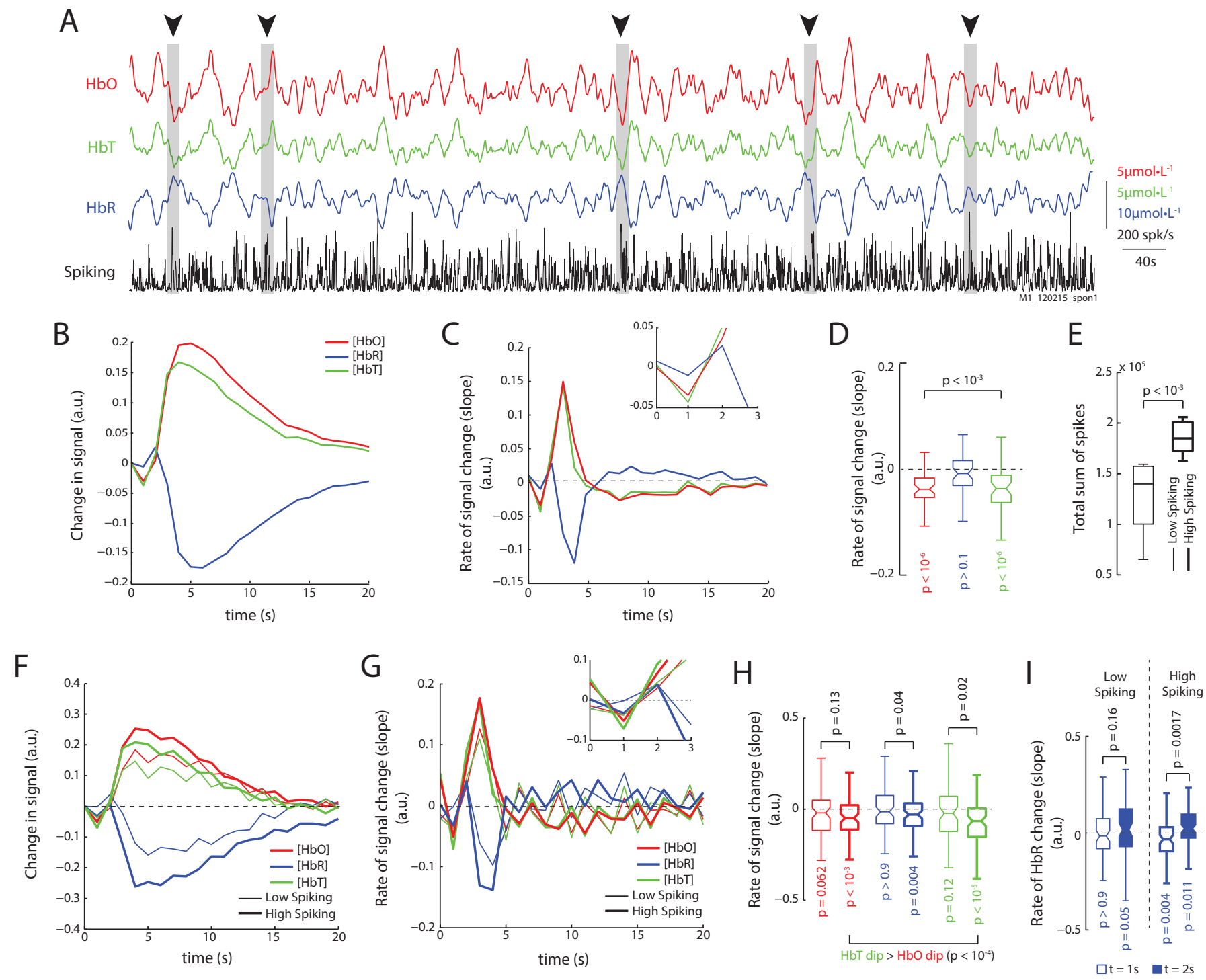

Figure 3. Analysis of spontaneous activity in the absence of visual stimulation reveals identical relationships. $\mathrm{A}) \mathrm{Traces}$ of $\mathrm{HbO}, \mathrm{HbR}, \mathrm{HbT}$ and spike-rates from an example run of 900s. Periods of high spiking activity that elicit an observable dip in $\mathrm{HbO}$ and $\mathrm{HbT}$ are marked with arrows and grey bars. B) We used system identification to estimate the impulse response functions from spiking to $\mathrm{HbO}, \mathrm{HbR}$ and $\mathrm{HbT}$ signals in recordings of spontaneous activity. The mean impulse response reveals a dip in $\mathrm{HbO}$ and $\mathrm{HbT}$ (mean of 48 impulse response functions obtained from 16 runs lasting 900s each; see Methods for details). C) Rate of change of the impulse response functions for $\mathrm{HbO}, \mathrm{HbR}$ and $\mathrm{HbT}$ reveals dips in both $\mathrm{HbO}$ and $\mathrm{HbT}$, and a late rise in the $\mathrm{HbR}$. Inset) Same traces but between 0 to $3 \mathrm{~s}$. D) Distribution of slopes for $\mathrm{HbO}, \mathrm{HbR}$ and $\mathrm{HbT}$ at $\mathrm{t}=1 \mathrm{~s}$. Only $\mathrm{HbO}$ and $\mathrm{HbT}$ have significant dips, but not $\mathrm{HbR}(\check{\mathrm{S}} ; \mathrm{n}=48$ ). E) The runs were divided based on the total sum of spikes in each run, and seperated into low spiking and high spiking runs. High spiking runs had signficanlty higher spike sums (Ś; $n=8)$. F) The mean impulse responses for high and low spiking runs reveal stronger modulation of hemodynamic signals on high spiking trials. Color-code same in following figures G) Mean traces of slopes of impulse responses shown in F. High spiking trials elicit an obvious dip at $t=1 \mathrm{~s}$. Inset) Same traces but from 0 to $3 \mathrm{~s}$. H) Distribution of dips for low and hihg spiking trials (legend same as F). Only high spiking trials have significant dips in all three signlas. Also, HbT dips were larger than HbO dips (Ś; n=80). I) When comparing the HbR dip and rebound at $\mathrm{t}=1 \mathrm{~s}$ and $\mathrm{t}=2 \mathrm{~s}$ resp., only high spiking trials reveal a strong dip and rebound in the $\mathrm{HbR}$ signal. 
bioRxiv preprint doi: https://doi.org/10.1101/259895; this version posted February 22, 2018. The copyright holder for this preprint (which was not certified by peer review) is the author/funder, who has granted bioRxiv a license to display the preprint in perpetuity. It is made available under aCC-BY-NC-ND 4.0 International license.

A

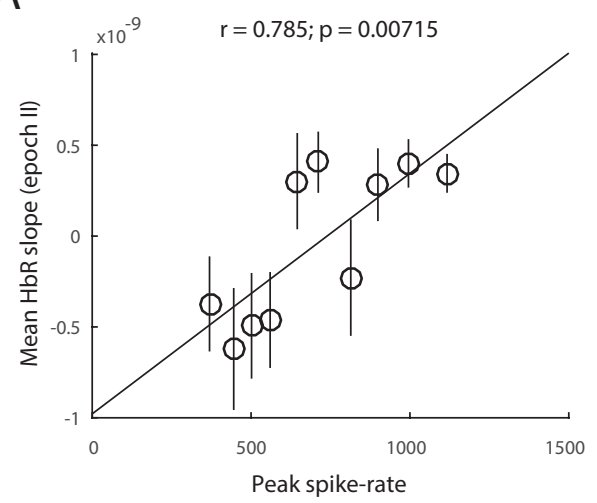

C
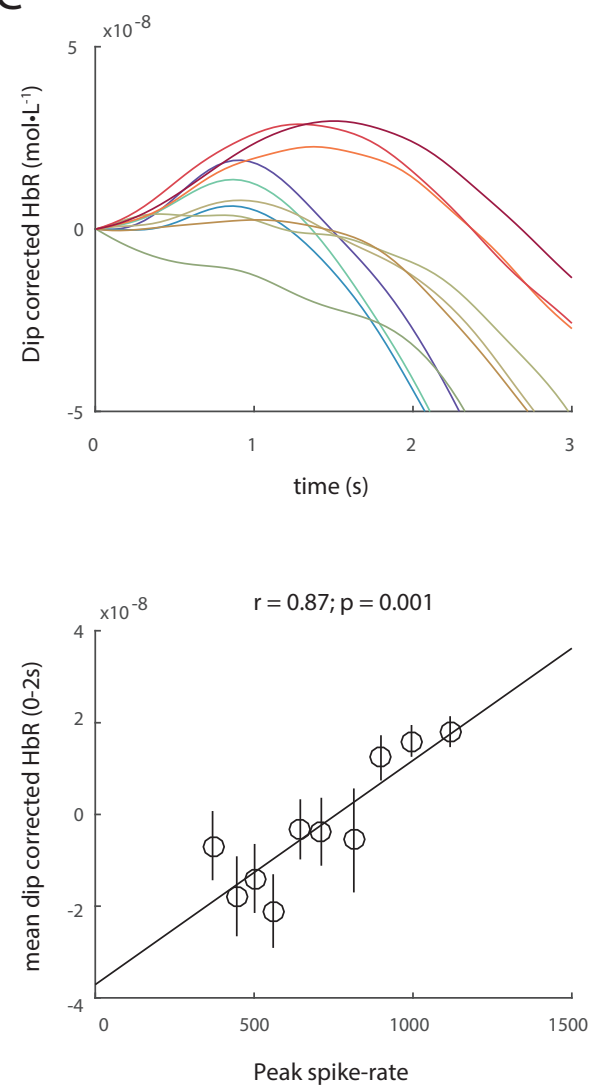

B

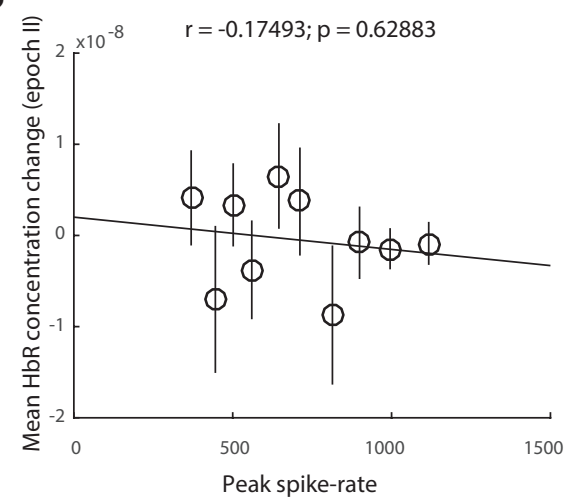

D
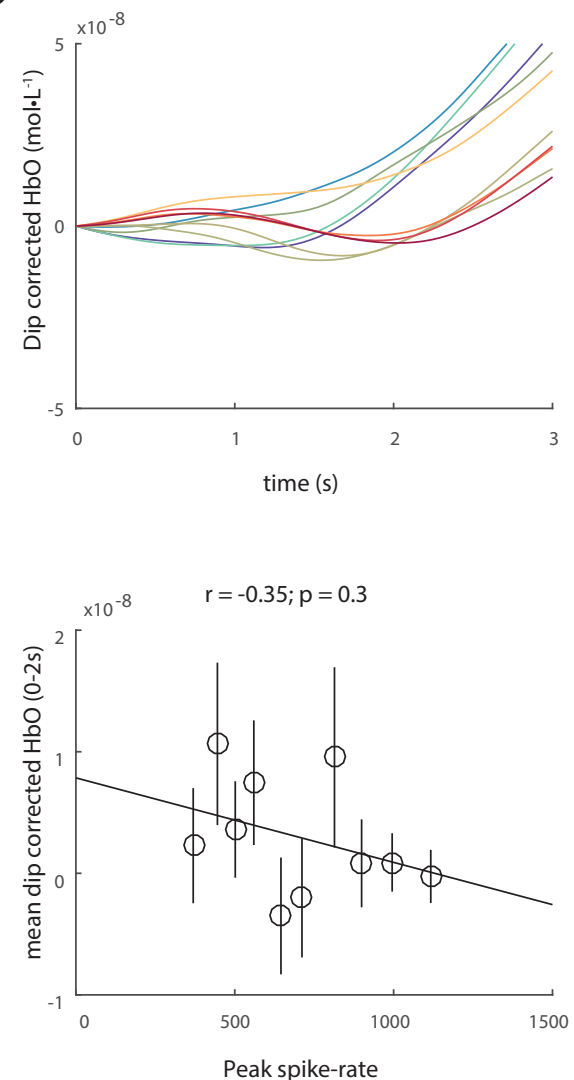

Figure 4. HbR-rebound does not lead to increase in HbR concentration. Although there is a significant correlation between spiking and the mean HbR slope in epoch II (A), the relative $\mathrm{HbR}$ concentration change remains unchanged with spiking (B). C) Dip-corrected HbR traces, obtained by imply subtracting the $\mathrm{HbT}$ traces from $\mathrm{HbR}$ reveals obvious increases in $\mathrm{HbR}$ concentration that correlate with spiking. However, no such relationship is observed with dip-corrected HbO traces. 
bioRxiv preprint doi: https://doi.org/10.1101/259895; this version posted February 22, 2018. The copyright holder for this preprint (which was not certified by peer review) is the author/funder, who has granted bioRxiv a license to display the preprint in perpetuity. It is made available under aCC-BY-NC-ND 4.0 International license.

15 Bins
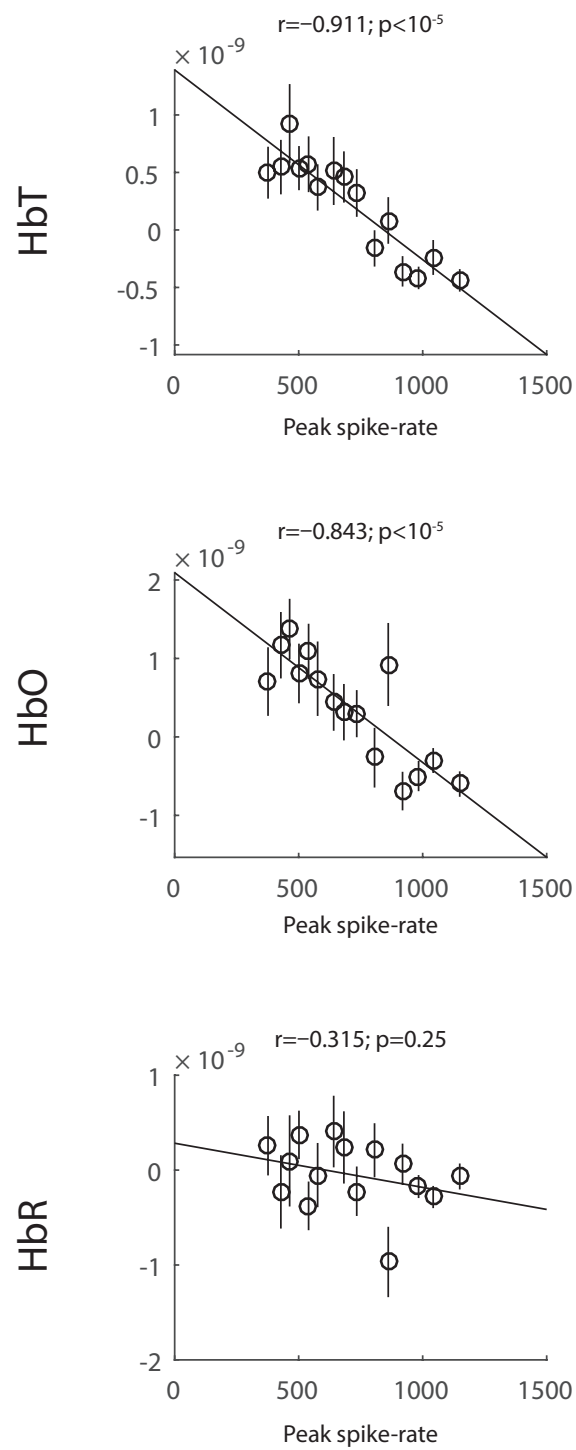

20 Bins
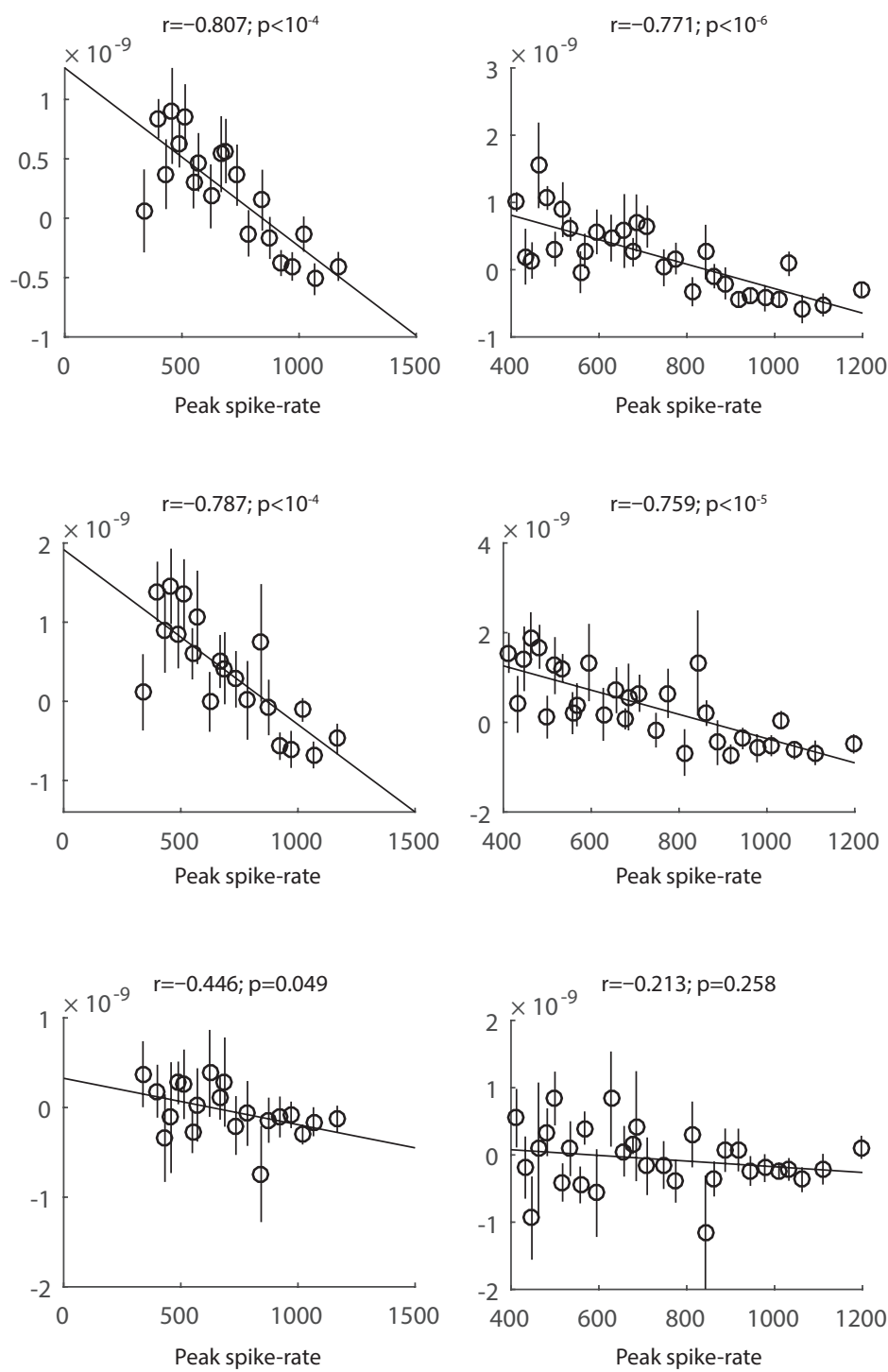

Figure S1. Related to Figure 1. Correlations of spiking activity with $\mathrm{HbT}$, HbO and HbR dips are independent of binsize. Although both $\mathrm{HbT}$ and $\mathrm{HbO}$ dips showed strong correlations with peaks in spike-rates, the correlations with $\mathrm{HbT}$ were stronger than $\mathrm{HbO}$. Although the strength of the correlations got weaker with increasing the number of bins, the significance was not very different. No correlations were observed with the dip strength in $\mathrm{HbR}$. These correlations were independent of the number of groups the data were divided into. 
bioRxiv preprint doi: https://doi.org/10.1101/259895; this version posted February 22, 2018. The copyright holder for this preprint (which was not certified by peer review) is the author/funder, who has granted bioRxiv a license to display the preprint in perpetuity. It is made available under aCC-BY-NC-ND 4.0 International license.

10 bins

$\mathrm{HbT}$
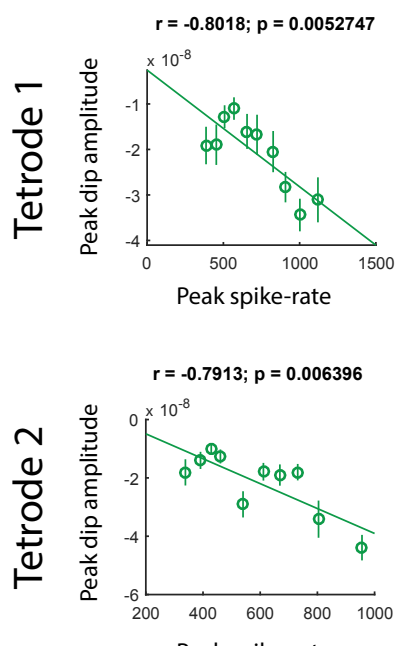

Peak spike-rate

$r=-0.4394 ; p=0.20388$

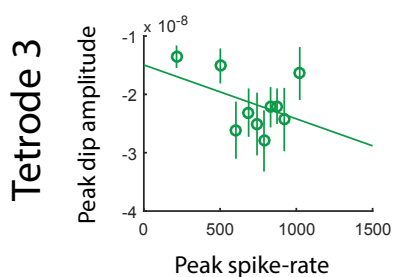

$\mathrm{HbO}$
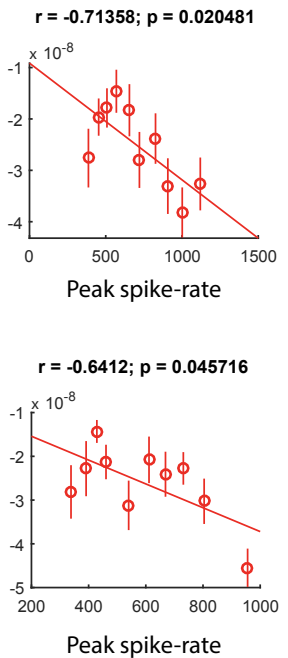

$r=-0.36031 ; p=0.30643$

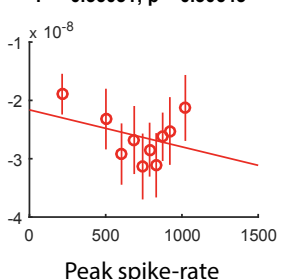

15 bins

HbT
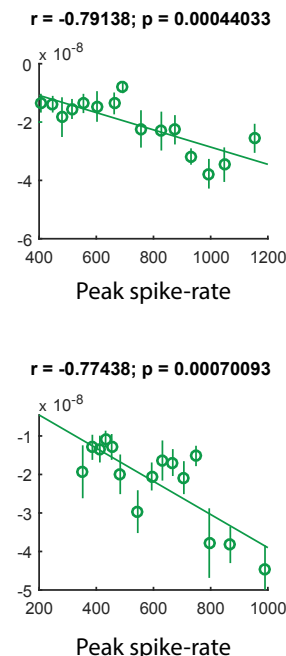

$r=-0.19739 ; p=0.48072$

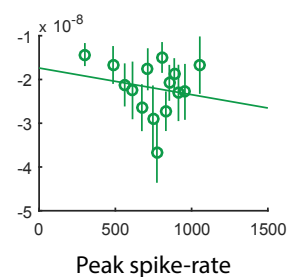

$\mathrm{HbO}$

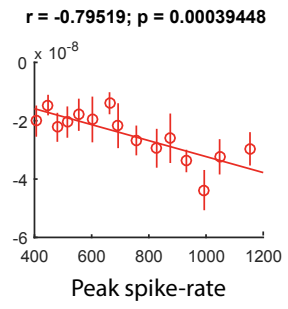

$r=-0.5576 ; p=0.030793$

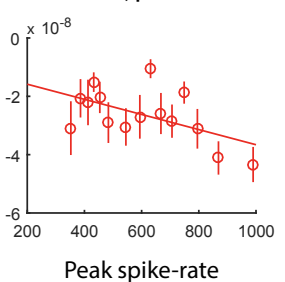

$r=-0.05347 ; p=0.84989$

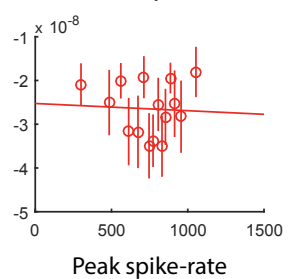

20 bins

HbT

$\mathrm{HbO}$
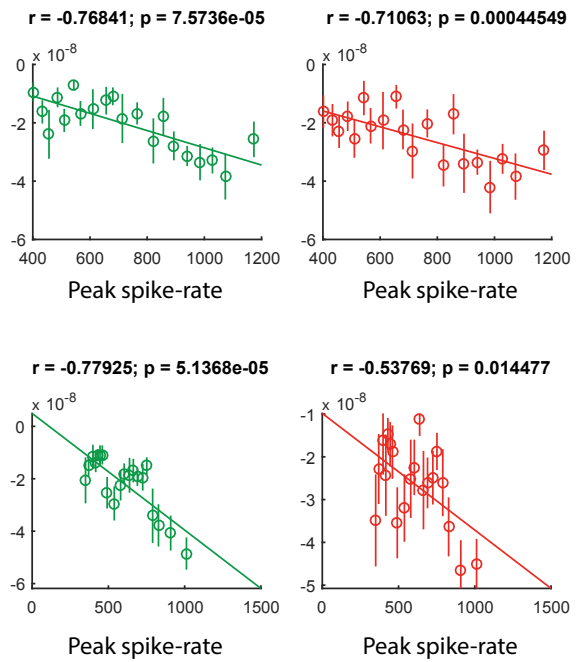

$r=-0.16208 ; p=0.49478$
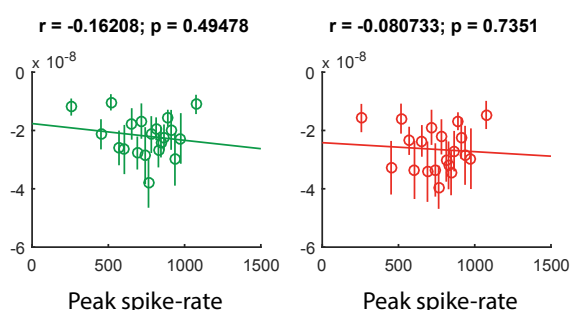

Figure S2. Related to Figure 1. Correlations between peak amplitude of inital dip and peak spike-rates across tetrodes. Instead of using the mean slope between $0-1 \mathrm{~s}$, we used the peak dip amplitude (minimum signal value between 0 and $3 \mathrm{~s}$ ) for $\mathrm{HbT}$ and $\mathrm{HbO}$ and correlated it with the peak spike-rate. We found that the correlations of peak dip amplitude with peak spike-rates were strongest on the tetrode closest to the emitter, and decreased with increasing distance of tetrode from emitter (see figure $2 \mathrm{H}$ for comparison). These results were independent of the number of bins the trials were divided into. These results demonstrate that both $\mathrm{HbO}$ and $\mathrm{HbT}$ dip amplitudes can be used a proxy for underlying spiking activity. 

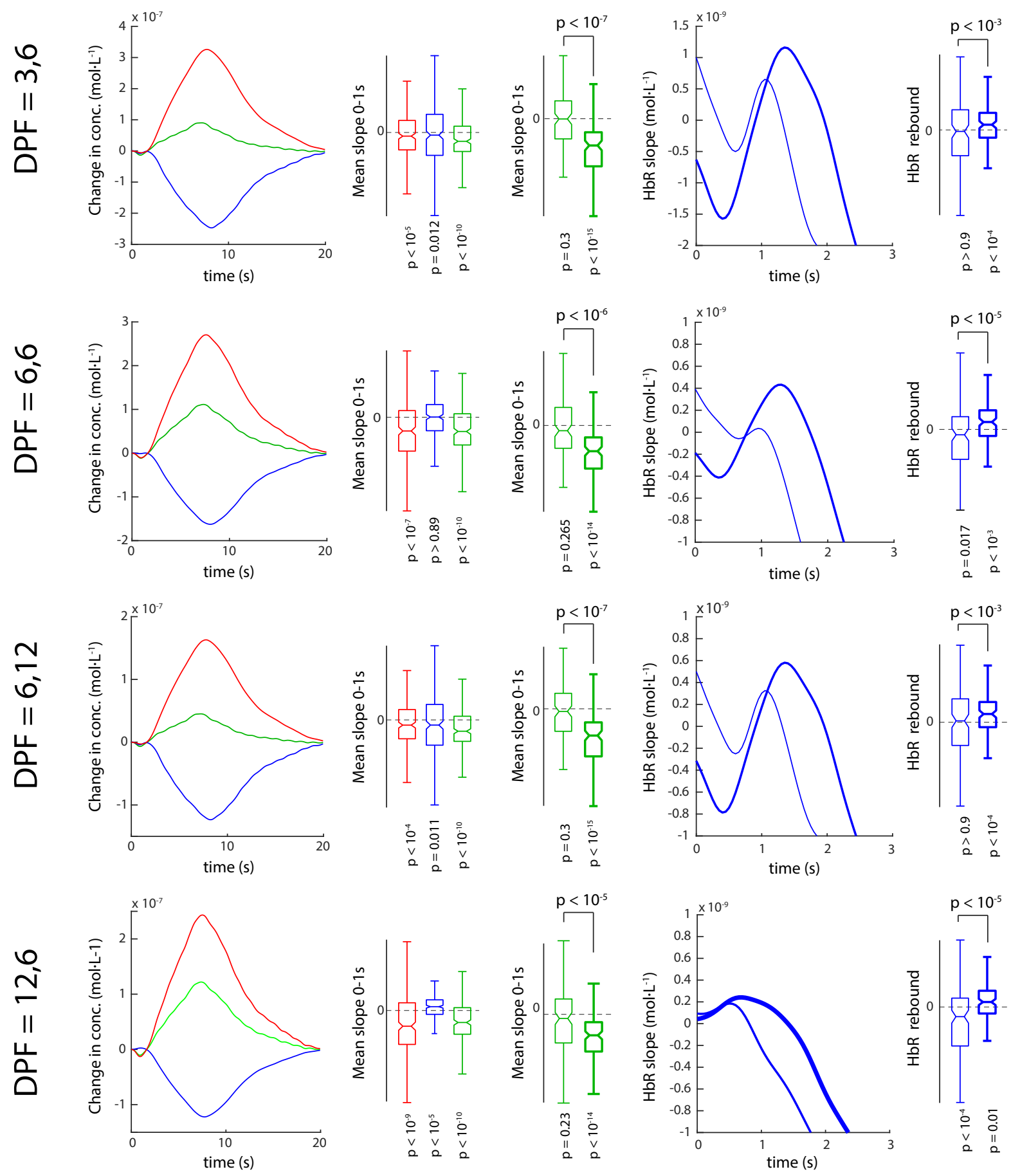

Figure S3. Verification of results across various differential path length factors (DPF). The conversion of optical density to concentration may vary based on the choice of DPF'. To ensure that our results did not depend on the DPF, we used multiple combinations of physiologically relevant DPF as reported earlier ${ }^{1}$ (the pair of values represent the DPFs at 760 and $850 \mathrm{~nm}$ resp.) and found that although different DPFs lead to a change in the amplitude of the signals, the overall results were not affected. For each combination of DPFs, we observed strong dips in the HbO and $\mathrm{HbT}$ signals. We also observed an increase in the dip strength for $\mathrm{HbT}$ during high spiking trials. Low spiking trials failed to elicit a significant dip. The HbR signal also elicited a strong dip and rebound modulation in each case. For each combination of DPFs, the results were nearly identical and individually significant.

Interestingly, the DFP combination 12,6 revealed increases in HbR within the $0-2 \mathrm{~s}$ of trial onset. However, there was no difference in $\mathrm{HbR}$ concentration in high-spiking vs low-spiking trials ( $p>0.4$; $\mathrm{n}=130$ /group, Wilcoxon rank-sum test). Furthermore, the strongest difference between high and low-spiking was still oberved in the HbT-dip ( $\left.p<10^{-5}\right)$ than HbO-dip $\left(p<10^{-3}\right)$.

This reaffirms previous results' that, at least in the primary visual cortex, although the choice of DPF might alter the amplitude of the calculated change in concentrations of $\mathrm{HbO}$, $\mathrm{HbR}$ and $\mathrm{HbT}$, it does not alter their relationship to underlying spiking activity. Notches represent $95 \%$ confidence intervals.

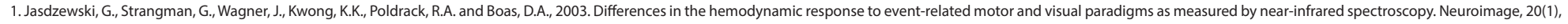
pp.479-488. 
bioRxiv preprint doi: https://doi.org/10.1101/259895; this version posted February 22, 2018. The copyright holder for this preprint (which was not certified by peer review) is the author/funder, who has granted bioRxiv a license to display the preprint in perpetuity. It is made available under aCC-BY-NC-ND 4.0 International license.

A

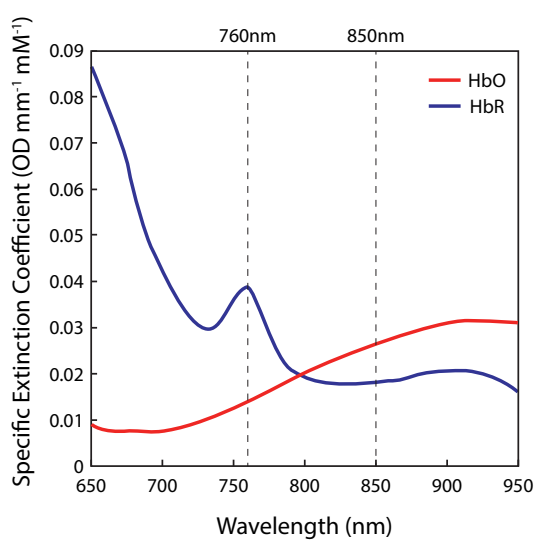

B

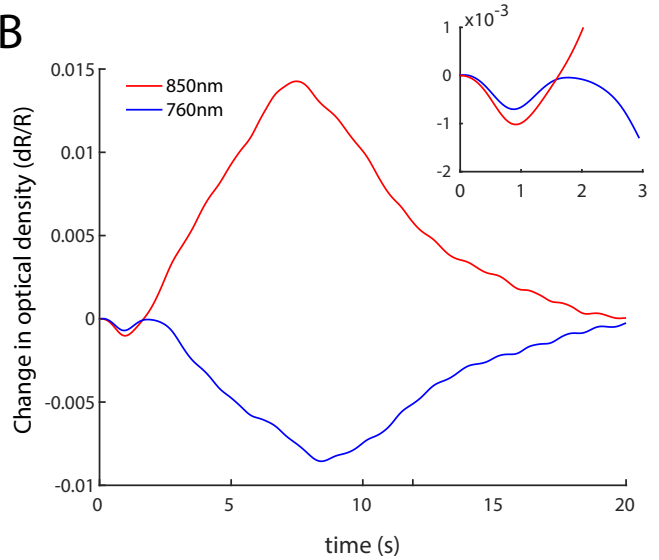

C

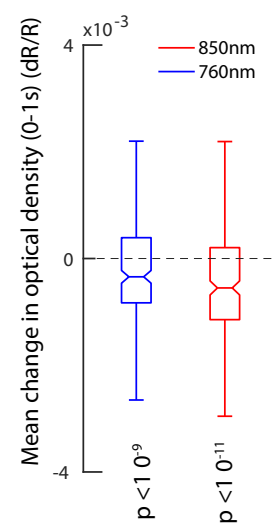

$\mathrm{D}$

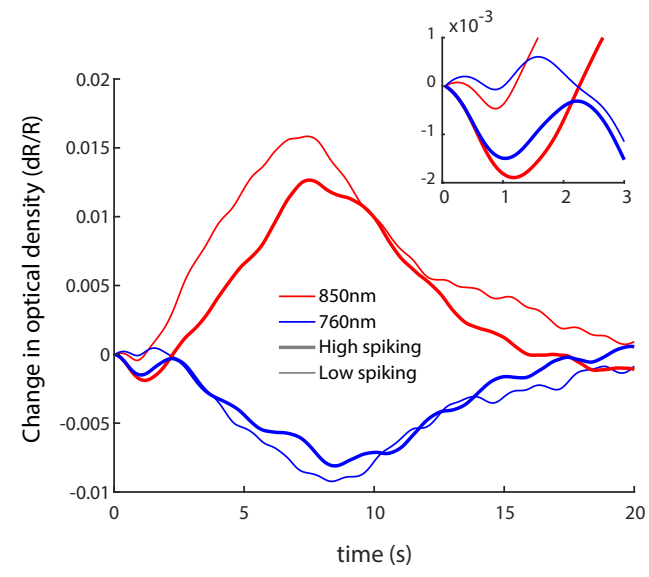

$\mathrm{E}$

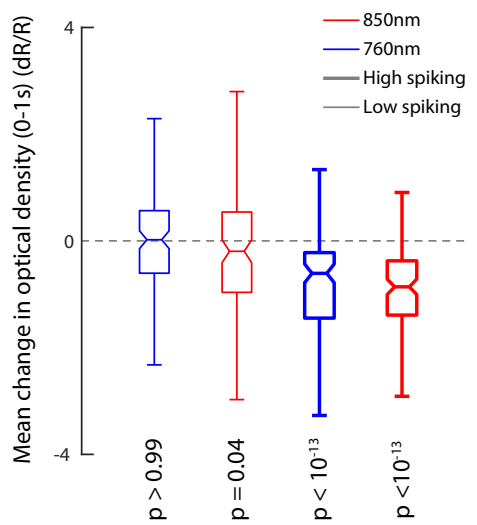

Figure S4. Changes in optical density for both imaging wavelenghts (760 $\mathrm{nm}$ and $850 \mathrm{~nm}$ ) reveal an early decrease in chromophore concentration. A) Specific extinction coefficients for $\mathrm{HbO}$ and $\mathrm{HbR}$ as a function of wavelength. Although both $\mathrm{HbO}$ and $\mathrm{HbR}$ absorb light at both wavelengths, 760nm is more sensitive to $\mathrm{HbR}$ changes whereas $850 \mathrm{~nm}$ is more sensitive to $\mathrm{HbO}$ changes. Changes in the observed optical density are proportional to changes in the chromatophores according to Beer's law. B) Mean changes in the optical densities at 760nm and $850 \mathrm{~nm}$ across all 260 trials. Inset represents the changes between 0-3s. A decrease in optical density for both wavelenghts can be observed. C) Mean change in optical density between 0 and 1s for 760 and 850 nm. The distributions are significanlty less than zero. D) Optical density changes for trials with high and low spiking activity. Inset represents the changes between 0-3s. Larger decreases in optical density are observed for the high spiking trials. E) Mean changes in optical density between 0-1s reveal significant decreases in optical density for high-spiking trials. The decrease in optical density for both chromatophores implies a decrease in both $\mathrm{HbO}$ and $\mathrm{HbR}$ concentrations. Since $\mathrm{HbT}$ is the sum of changes in $\mathrm{HbO}$ and $\mathrm{HbR}$, simultaneous decreases in $\mathrm{HbO}$ and $\mathrm{HbR}$ would lead to larger decreases in $\mathrm{HbT}$ when changes in optical density are converted to changes in concentration. Surprisingly, we found mildly significant decreases in the optical density at $850 \mathrm{~nm}$ for low-spiking trials. However, after conversion to concentration changes, none of the traces ( $\mathrm{HbO}$, $\mathrm{HbR}$ or $\mathrm{HbT}$ ) revealed significant changes between 0-1s. 
bioRxiv preprint doi: https://doi.org/10.1101/259895; this version posted February 22, 2018. The copyright holder for this preprint (which was not certified by peer review) is the author/funder, who has granted bioRxiv a license to display the preprint in perpetuity. It is made available under aCC-BY-NC-ND 4.0 International license.

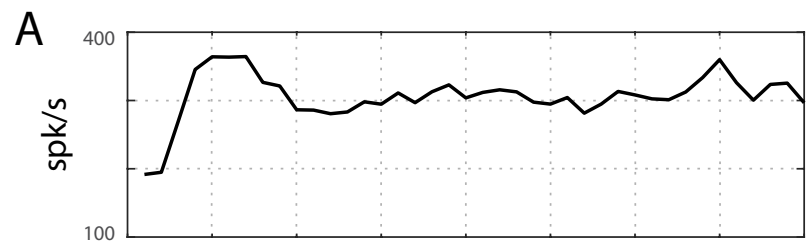

B

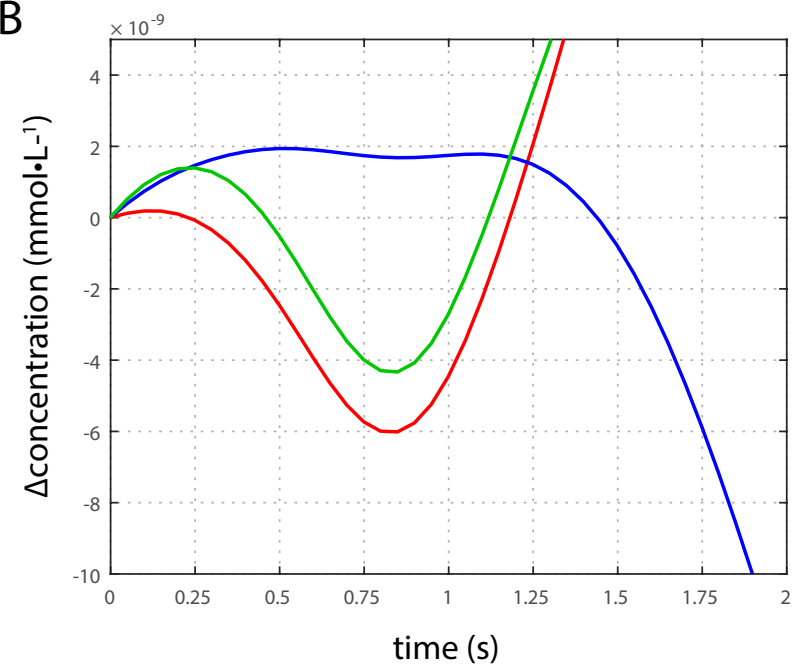

C

P-value of mean concentration change within window of 0 to $t(s)$

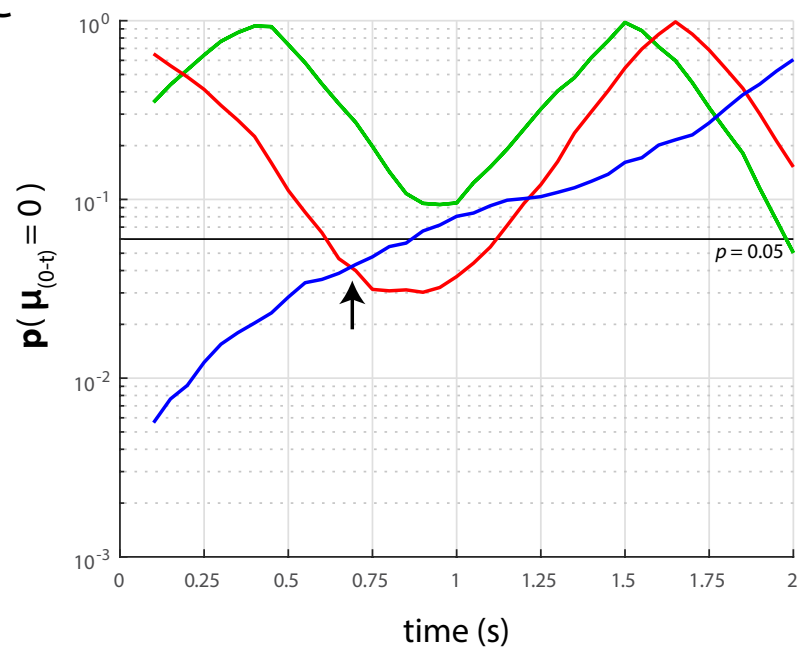

Figure S5. Further analysis of low-spiking trials reveals a significant increase in $\mathrm{HbR}$ and decrease in $\mathrm{HbO}$ concentrations within the first $\mathbf{7 5 0 m s}$. We further analyzed trials where the peak spike-rate was less than the median value of all trials (A, see also Figure $2 \mathrm{~A}$ ). Although these trials belonged to the lower half of the distribution, they still had significantly high peak spike-rates and stimulus induced spike-rate moduations (see Fig. 2D). We obtained the mean $\mathrm{HbO}, \mathrm{HbR}$ and $\mathrm{HbT}$ traces from these trials (B). Increases in $\mathrm{HbR}$ traces and decreases in the $\mathrm{HbO}$ traces are clearly observable within these trials. We determined the temporal window within which these changes were significant, by incrementing the width of the window from 0 to $2 \mathrm{~s}(\mathbf{C}$, p $<0.05$ based on the Wilcoxon signed-rank test). We found the changes to be significant for $\mathrm{HbO}$ and $\mathrm{HbR}$ within $0-0.7 \mathrm{~s}$ of stimulus onset (arrow). We failed to find significant changes for $\mathrm{HbT}$ for the same period (C, green trace). These findings demonstrate that during conditions of low spiking, the initial-dip consists of increases in $\mathrm{HbR}$ and decreases in $\mathrm{HbO}$, and the HbT dip is absent. This suggets that the HbT dip is only induced during conditions of strong bursts in spiking activity. 
bioRxiv preprint doi: https://doi.org/10.1101/259895; this version posted February 22, 2018. The copyright holder for this preprint (which was not certified by peer review) is the author/funder, who has granted bioRxiv a license to display the preprint in perpetuity. It is made available under aCC-BY-NC-ND 4.0 International license.

Supplementary table 1. Hemodynamic initial dips during spontaneous and stimulus-induced activity.

\begin{tabular}{|c|c|c|c|c|c|c|}
\hline dataset & parameter & condition & mean & SEM & p-value ${ }^{*}$ & Sample-size \\
\hline \multirow{19}{*}{ Stimulus-induced activity } & \multirow{3}{*}{$\begin{array}{l}\text { Peak spike-rate } \\
(\mathrm{spk} / \mathrm{s})\end{array}$} & all trials & 705.85 & 14.7 & $<10^{-10}$ & 260 \\
\hline & & high-spiking & 899.96 & 12.89 & $<10^{-10}$ & 122 \\
\hline & & Low-spiking & 497.28 & 8.35 & $<10^{-10}$ & 125 \\
\hline & \multirow{3}{*}{$\begin{array}{l}\text { HbO dip } \\
\left(\mu \mathrm{mol} \cdot \mathrm{L}^{-1}\right)\end{array}$} & All trials & -0.52 & 0.12 & $<10^{-7}$ & 260 \\
\hline & & high-spiking & -0.87 & 0.146 & $<10^{-11}$ & 122 \\
\hline & & Low-spiking & -0.22 & 0.188 & 0.21 & 125 \\
\hline & \multirow{3}{*}{$\begin{array}{l}\text { HbR dip } \\
\left(\mu \mathrm{mol} \cdot \mathrm{L}^{-1}\right)\end{array}$} & All trials & -0.04 & 0.078 & 0.89 & 260 \\
\hline & & high-spiking & -0.2 & 0.089 & 0.0076 & 122 \\
\hline & & Low-spiking & 0.09 & 0.12 & 0.18 & 125 \\
\hline & \multirow{3}{*}{$\begin{array}{l}\text { HbT dip } \\
\left(\mu \mathrm{mol} \cdot \mathrm{L}^{-1}\right)\end{array}$} & All trials & -0.56 & 0.11 & $<10^{-10}$ & 260 \\
\hline & & High-spiking & -1.08 & 0.112 & $<10^{-14}$ & 122 \\
\hline & & Low-spiking & -0.13 & 0.179 & 0.287 & 125 \\
\hline & \multirow{3}{*}{$\begin{array}{l}\text { HbR buildup } \\
\left(\mu \mathrm{mol} \cdot \mathrm{L}^{-1}\right)\end{array}$} & All trials & -0.041 & 0.805 & 0.634 & 260 \\
\hline & & High-spiking & 0.236 & 0.093 & $<10^{-3}$ & 122 \\
\hline & & Low-spiking & -0.365 & 0.133 & 0.007 & 125 \\
\hline & \multirow{3}{*}{$\begin{array}{l}\text { HbR- modulation } \\
\text { (epoch II - epoch I) }\end{array}$} & All trials & 0.029 & 0.095 & 0.135 & 260 \\
\hline & & High-spiking & 0.534 & 0.077 & $<10^{-10}$ & 122 \\
\hline & & Low-spiking & -0.481 & 0.165 & $<10^{-3}$ & 125 \\
\hline & $\mathrm{HbO} / \mathrm{HbT} \operatorname{dip}(\%)$ & High-spiking & 50.36 & 17 & - & 122 \\
\hline \multirow{17}{*}{ Spontaneous activity } & \multirow{3}{*}{ Total spike count } & All runs & $1.56 \times 10^{5}$ & $1.03 \times 10^{4}$ & $<10^{-3}$ & 16 \\
\hline & & High-spiking & $1.86 \times 10^{5}$ & $5.81 \times 10^{3}$ & 0.0078 & 8 \\
\hline & & Low-spiking & $1.27 \times 10^{4}$ & $1.36 \times 10^{4}$ & 0.0078 & 8 \\
\hline & \multirow{3}{*}{$\begin{array}{l}\text { HbO dip } \\
\quad \text { (a.u.) }\end{array}$} & All runs & -0.034 & 0.005 & $<10^{-6}$ & 48 \\
\hline & & High-spiking & -0.051 & 0.012 & $<10^{-3}$ & 80 \\
\hline & & Low-spiking & -0.036 & 0.015 & 0.06 & 80 \\
\hline & \multirow{3}{*}{$\begin{array}{l}\text { HbR dip } \\
\quad \text { (a.u.) }\end{array}$} & All runs & -0.009 & 0.005 & 0.1 & 48 \\
\hline & & High-spiking & -0.032 & 0.014 & 0.0041 & 80 \\
\hline & & Low-spiking & -0.001 & 0.016 & 0.9 & 80 \\
\hline & \multirow{3}{*}{$\begin{array}{l}\text { HbT dip } \\
\quad \text { (a.u.) }\end{array}$} & All runs & -0.043 & 0.007 & $<10^{-6}$ & 48 \\
\hline & & High-spiking & -0.07 & 0.016 & $<10^{-5}$ & 80 \\
\hline & & Low-spiking & -0.037 & 0.018 & 0.122 & 80 \\
\hline & \multirow{2}{*}{$\begin{array}{l}\text { HbR buildup } \\
\quad \text { (a.u.) }\end{array}$} & High-spiking & 0.04 & 0.0136 & 0.011 & 80 \\
\hline & & Low-spiking & 0.039 & 0.012 & 0.049 & 80 \\
\hline & \multirow{2}{*}{ HbR- modulation } & High-spiking & 0.072 & 0.024 & $0.0017 \dagger$ & 80 \\
\hline & & Low-spiking & 0.041 & 0.031 & $0.16 \dagger$ & 80 \\
\hline & $\mathrm{HbO} / \mathrm{HbT} \operatorname{dip}(\%)$ & High-spiking & 58.9 & 32 & - & 48 \\
\hline
\end{tabular}

${ }^{*}$ Wilcoxon's two-tailed sign-rank test

$\dagger$ Wilcoxon's one-tailed sign-rank test 